\title{
Perceptual differentiation as a source of category effects in object processing: Evidence from naming and object decision
}

\author{
TOBY J. LLOYD-JONES \\ University of Kent, Canterbury, England \\ and \\ GLYN W. HUMPHREYS \\ University of Birmingham, Birmingham, England
}

\begin{abstract}
The locus of category effects in picture recognition and naming was examined in two experiments with normal subjects. Subjects carried out object decision (deciding whether the stimulus is a "real" object or not) and naming tasks with pictures of clothing, furniture, fruit, and vegetables. These categories are distinguished by containing either relatively many exemplars with similar perceptual structures (fruit and vegetables; structurally similar categories), or relatively few exemplars with similar perceptual structures (clothing and furniture; structurally dissimilar categories). In Experiment 1, responses to the stimuli from the structurally similar categories were slower than responses to stimuli from the structurally dissimilar categories, and this effect was larger in the naming than in the object decision task. Further, prior object decisions to stimuli from structurally similar categories facilitated their subsequent naming. In Experiment 2, we orthogonally manipulated object decision and naming as prime and target tasks, again with stimuli from the four categories. Category effects, with responses slower to objects from structurally similar categories, were again larger in naming than in object decision, and these category effects in naming were reduced by priming with both naming and object decision. We interpret the data to indicate that category effects in object naming can reflect visually based competition which is reduced by the preactivation of stored structural knowledge for objects.
\end{abstract}

How may object recognition and identification be constrained by the nature and kind of object that the system has to process? Both recent work with normal observers (e.g., Humphreys, Riddoch, \& Quinlan, 1988; Price \& Humphreys, 1989) and studies of patients with impaired recognition (e.g., Riddoch \& Humphreys, 1987a; Sartori \& Job, 1988; Silveri \& Gainotti, 1988; Warrington \& Shallice, 1984) have demonstrated category-specific differences can arise in object recognition and naming. Such work suggests that object recognition is constrained by the nature of the object to be processed. Nevertheless, different accounts of the form of such constraints are possible. The most striking evidence for recognition differences across semantic categories of objects comes from the neurological literature.

\section{Neuropsychological Evidence}

A number of reports have been made of patients who are impaired in the recognition of living as opposed to

This work was supported by Grant R-000-23-2412 from the Economic and Social Research Council of Great Britain to the second author. We would like to thank Geoffery R. Loftus, Stephen J. Lupker, and two anonymous reviewers for their helpful comments. Reprint requests should be sent to T. J. Lloyd-Jones, Cognitive Neuroscience Research Centre, Department of Psychology, University of Kent, Canterbury, Kent CT2 7LZ, England (e-mail: t.j.lloyd-jones@ukc. ac.uk). nonliving objects (e.g., Farah, McMullen, \& Meyer, 1991; Riddoch \& Humphreys, 1987a; Sartori \& Job, 1988; Sartori, Job, \& Coltheart, 1993; Sheridan \& Humphreys, 1993; Silveri \& Gainotti, 1988). In some cases, recognition performance appears to be relatively good, and the category effects seem to be confined to name retrieval (Sartori, Job, \& Coltheart, 1993). Consistent with this, selective deficits in name retrieval only for the categories of fruit and vegetables have been reported (Farah \& Wallace, 1992; Hart, Bernt, \& Caramazza, 1985).

Warrington and Shallice (1984) originally proposed that the relatively poor identification of living things was produced by selective impairment to a particular form of stored knowledge. Living things may be represented primarily by their sensory attributes, whereas nonliving things may be represented in terms of their functional attributes (e.g., color may be the critical attribute for distinguishing two fruits, but "when worn" may be the essential attribute for distinguishing different clothes). More recently, Farah and McClelland (1991) have instantiated such an account in a connectionist model. The model successfully simulated selective impairment of knowledge of living things and further simulated the finding of a selective impairment for living things whereby patients are impaired at accessing functional as well as visual information about living things-a finding which had been considered as posing a problem for the sen- 
sory-functional hypothesis (Farah \& McClelland, 1991).

Other investigators have argued that category-specific deficits in the identification of living things may be artifactual (e.g., Funnell \& Sheridan, 1992; Stewart, Parkin, \& Hunkin, 1992). For example, Funnell and Sheridan propose that semantic category effects will disappear when correlates such as familiarity, complexity, and name frequency are properly controlled. Nevertheless, patients have been reported who still show impaired recognition of living things when these confounding factors are eliminated, either through the use of lists of items matched for these factors (e.g., Sartori et al., 1993; Sheridan \& Humphreys, 1993), or by partialling out these factors statistically (Farah et al., 1991). In addition, the opposite dissociation of impaired recognition of nonliving objects has also been reported (Hillis \& Caramazza, 1991; Sacchett \& Humphreys, 1992; Warrington \& McCarthy, 1983, 1987), and this would not be likely to arise were familiarity, complexity, and name frequency the only factors accounting for these problems (nonliving things in general are, for example, more familiar and have highly frequent names).

It is also difficult, however, to attribute all categoryspecific disturbances in the neuropsychological literature to selective losses of either stored perceptual or functional knowledge. Patients with impaired recognition of living things have been reported who nevertheless maintain good access to stored perceptual knowledge. These patients are able to perform well with living things on difficult object decision tasks despite showing poor recognition of the same stimuli (e.g., being unable to perform associative matches between the stimuli; Riddoch \& Humphreys, 1987a; Sheridan \& Humphreys, 1993). The object decision task requires judgments as to whether objects are real or not (see, e.g., Kroll \& Potter, 1984). Subjects are presented with a series of pictures of objects interspersed with an equal number of nonobjects, which can be created in various ways - for example, by adding a spurious feature or by replacing a part of one object with a part of another object from a different category. Difficult object decision tasks (where, e.g., nonobjects are constructed by interchanging parts of objects within class) require access to stored perceptual knowledge about the objects involved. Furthermore, selective deficits confined to naming stimuli from some categories of living things, along with good recognition of the same stimuli, seem unlikely to reflect impaired perceptual knowledge which would be required for recognition as well as naming (see, e.g., Hart et al., 1985).

\section{Normal Object Naming}

An alternative account of why selective deficits in the recognition and naming of living things may sometimes arise attributes these deficits to processing differences that occur during normal object naming. Most current models propose that object naming involves access to, and retrieval of, three kinds of stored information (e.g., Ellis \& Young, 1988; Humphreys et al., 1988; Seymour, 1979, Snodgrass, 1984; Warren \& Morton, 1982). Visual input is matched to a stored representation of the object's form and structure (i.e., a structural representation), accessing this stored visual representation enables further access to conceptual and/or functional information about the object, and subsequently the object's name is retrieved. The distinction between these processing stages is supported by studies of normal object processing (e.g., Glaser, 1992; Riddoch \& Humphreys, 1987b; Seymour, 1979; Snodgrass, 1984; see also Cooper, Schacter, Ballesteros, \& Moore, 1992; Schacter, Cooper, \& Delaney, 1990a, 1990b; Schacter, Cooper, Delaney, Peterson, \& Tharan, 1991), and by neuropsychological evidence of selective deficits in accessing different forms of stored information (e.g., Riddoch \& Humphreys, 1987a; Sheridan \& Humphreys, 1993).

Humphreys et al. (1988; see also Riddoch \& Humphreys, 1987b) have suggested that living things typically are globally visually similar and share more common parts with other members of their categories than do nonliving things. These differences in the degree of overlap of the perceptual structures of living and nonliving things may have important consequences for visual object recognition and naming. In particular, if partial activation is transmitted from one stage to another during object processing, objects with greater perceptual similarity within their classes will be subject to greater competition at all levels within the system. This competition may initially arise in the accessing of stored perceptual knowledge about objects ("the structural description system"; Riddoch \& Humphreys, 1987b). However, for a system operating in "cascade," competition at the perceptual level may in turn generate increased competition in the accessing of both functional/semantic and name information.

The cascade model of Humphreys et al. (1988; see Figure 1) proposes that activation is transmitted continuously from units at different levels of representation. There are excitatory connections between consistent units (e.g., between the structural representations of cat and dog, which share perceptual features in common; between the structural and semantic representations of cat; or between the semantic representations of $c a t$ and $d o g$ ), and inhibitory connections between inconsistent units (e.g., between the structural representations of cat and trousers, which share no features in common; or between the structural representation of cat and the semantic representation of $d o g$ ). Presentation of a stimulus that shares perceptual features (including overall shape) with many other items will activate the structural descriptions of many other items, relative to presentation of a stimulus that shares only few features with other objects. As a consequence of this, presentation of a "structurally similar" stimulus will activate not only its own semantic representation, but also, through co-activation of the structural descriptions of perceptually similar objects, semantic representations of items that are perceptually similar (mainly items from the same category but also perceptually similar items that are not categorically related). To give a simple illustration, presentation of cat 


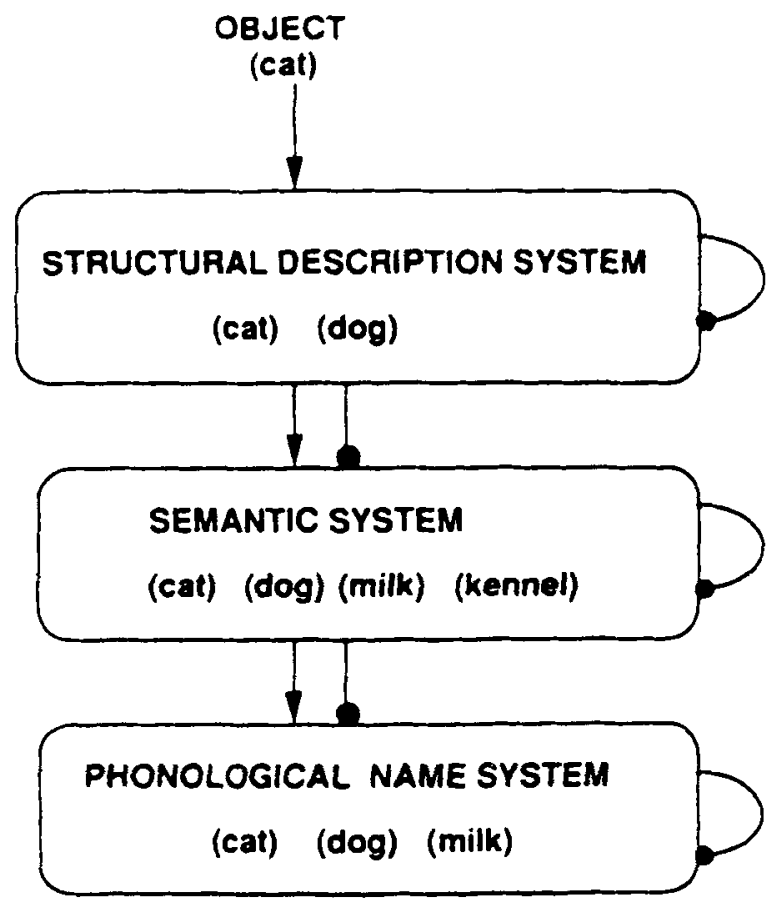

Figure 1. A framework illustrating the cascade model of picture naming (Humphreys, Riddoch, \& Quinlan, 1988). Activation is transmitted continuously from units at different levels of representation in the model. There are excitatory connections $(\rightarrow)$ between consistent units and inhibitory connections $(-\bullet)$ between inconsistent units.

will activate the structural description of $d o g$; in turn, the semantic representations of cat, dog, milk, and kennel will be activated. As a consequence of this, the phonological representations of both the target and perceptually and semantically related neighbors will be activated (and possibly also representations of items phonologically related to semantically similar competitors; see Dell \& O'Seaghdha, 1989; Levelt et al., 1991). In contrast, for items that share few perceptual features with other items, the object naming system is initially less activated, the target is subject to less competition at each of the levels of representation, and processing proceeds more directly. From such a model, we propose that competition becomes more and more fierce as activation spreads through the system. Hence, tasks that tap relatively late stages of the system (such as naming) should show greater perceptual category differences in ease of processing when compared with tasks that tap earlier stages of the system (such as object decision).

A variety of evidence is consistent with a continuous processing account of category differences in object processing (Humphreys et al., 1988; Riddoch \& Humphreys, 1987b; for reviews, see Lloyd-Jones, 1992; Humphreys, Lamote, \& Lloyd-Jones, 1995; Vitkovitch, Humphreys, \& Lloyd-Jones, 1993).

Returning now to the neurological deficits outlined earlier: neurological impairments may exacerbate previously existing processing differences. A change in effi- ciency of the process of perceptual differentiation may have important consequences for both the retrieval of functional/semantic knowledge about an object and the ability to name it.

\section{The Present Experiment}

The following prediction arises from the processing account of category differences in object naming: small contrasts in the ease of accessing structural information for objects may in turn generate larger category differences in accessing functional/semantic and name information. The "deeper" in the system that processing is tapped, the greater the competition for objects that share greater perceptual overlap with other objects from the same class. It follows that, for these classes of objects, there will be large costs in terms of response time/accuracy, in reducing competition in order to retrieve item-specific names. In contrast, when the task taps an earlier stage in processing, competition should be less and hence the difference between the two classes of objects should be less pronounced. We tested this prediction by comparing performance on object decision, where neuropsychological evidence suggests that access only to stored structural information concerning objects is necessary, with that of naming where access to structural, functional/semantic, and phonological knowledge is required.

In the following experiment, the objects were drawn from categories with either many or relatively few perceptually similar exemplars--fruit and vegetables in one instance, and clothing and furniture in the other. Independent evidence for this distinction comes from measures of contour overlap and number of partonomic features in common (see Humphreys et al., 1988; Riddoch \& Humphreys, 1987b). Subjects first either named or made object decisions to fruit, vegetables, items of clothing, or furniture, and then performed the opposite task on the same stimuli.

\section{EXPERIMENT 1}

\section{Method}

Subjects. There were 30 subjects (both male and female). All were paid members of the Birkbeck College subject pool, and all had normal or corrected-to-normal vision. Further, all were native English speakers and had not seen the pictures before. Each subject participated in a single experimental session lasting about $45 \mathrm{~min}$.

Stimuli and Apparatus. Four categories of object were used: clothing, furniture, fruit, and vegetables. There were 72 line drawings of objects ( 18 per category) paired with 72 line drawings of nonobjects. Category exemplars were chosen from Rosch's (1975) norms and were selected from the whole range of typicality within each category. Drawings of objects were selected from the standardized set of Snodgrass and Vanderwart (1980), and added to these were further drawings by a trained artist (the first author). The creation of these additional drawings was constrained by the criteria of Snodgrass and Vanderwart (1980), namely: Objects whose up-down orientation could vary (e.g., a fork) were drawn with the functional end down; long, thin objects were oriented at a $45^{\circ}$ angle, with equal numbers in the two possible orientations; and the objects were drawn so as to be of approximately equal size 
within and across categories (so that objects in one category were judged to be no larger than those in another), in accordance with the decision of three independent judges.

Name agreement for the new drawings was assessed by presenting an independent group of 12 subjects with the complete set of potential stimuli. As in Snodgrass and Vanderwart (1980), each subject was shown each picture for a period of 3-5 sec and was asked to write down the name of the object. If they did not know the name, they were asked to mark one of the following categories: don't know name; don't know object; tip-of-the-tongue. Following this procedure, only drawings of objects with greater than $75 \%$ name agreement were used. It might be argued that such a liberal criterion could cause low name agreement to contribute to any baseline differences and/or priming effects between categories (e.g., because of less name agreement, there is greater priming for vegetable and fruit categories). In the present case, however, this would not be name agreement as it is usually defined (i.e., alternative names for an object such as oven/cooker), since individual fruit and vegetables do not have alternative names; rather, it would reflect a difficulty in putting names to objects that look similar (e.g., plum/grape), which is concomitant with manipulating perceptual similarity. That is, it would be a problem of making withincategory perceptual discriminations. Thus a slightly less conservative name agreement criterion is not a confound as such; by this definition, it is rather a function of perceptual similarity.

Nonobjects for the object decision task were constructed by exchanging/rotating single parts belonging to objects from the same category (e.g., replacing the collar of a coat with the sleeve of a jumper). Examples of nonobjects are given in Appendix A. It should be noted that other types of nonobjects are possible. For example, parts may be exchanged between as well as within categories (Humphreys et al., 1988), or completely novel items may be created (Kroll \& Potter, 1984). As with the set of nonobjects created by Kroll and Potter, the present nonobjects were created to have all the Gestalt properties of pictures of real objects. Thus, subjects should not be able to respond accurately on the basis of gross figural differences between the objects and nonobjects. Rather, correct responding should be based on reference to stored structural knowledge concerning particular objects; access to at least a structural representation would seem to be required. In addition, we obtained ratings on the "objectness" of structurally similar and structurally dissimilar nonobjects. On a scale of $1-7$, 10 subjects rated the degree to which each nonobject picture either looks very much like a real object or looks nothing like a real object (cf. Kroll \& Potter, 1984). There was no difference between the categories, with a mean rating of $3.3(S D=0.84)$ for structurally dissimilar nonobjects and $3.7(S D=0.96)$ for structurally similar nonobjects.

The complete list of objects is presented in Appendix B. The stimuli were presented on a two-field tachistoscope. Latencies in vocalizing (measured in milliseconds) were obtained by interfac- ing the tachistoscope with a crystal clock and voice-activated relay, so that the timing cycle began with the onset of the target stimulus and terminated with the subject's response.

Design and Procedure. In separate blocks of trials, subjects performed either a naming or an object decision task, with the same pictures of objects. Half the subjects performed the naming task first, and half, the object decision task first. Thus, task order was a between-groups factor. Task and category (structurally similar vs. structurally dissimilar) were repeated measures. There was a period of 10-15 min between completing the first and starting the second task.

For the object decision task, subjects made a verbal rather than a keypress yes/no classification decision. This was in order not to confound task and type of response. Nevertheless, it should be noted that since a picture-naming response may be the name of essentially any picturable concept, a binary yes/no decision should represent an advantage at the response and execution levels (Lupker, 1985).

Before starting the experiment, subjects viewed the whole set of stimuli in order to reduce the effects of familiarity on performance and to minimize carryover/practice effects between the two tasks. Presentation order was randomized for each subject within tasks, with the constraint that each stimulus was not preceded by an item from the same category on the previous two trials, to reduce intertrial priming.

For the naming task, there were 20 practice and 72 experimental trials; for the object decision task, there were 20 practice and 144 experimental trials. Practice stimuli came from categories other than those used in the experimental trials.

\section{Results}

The mean correct reaction times (RTs) were collated. A trial was scored an error if (1) the subject stuttered or misnamed the target, (2) the naming latency was $2 S D$ s above or below the mean for that subject in that particular condition, ${ }^{1}$ or (3) a machine error occurred. In the error analysis, only trials falling into categories (1) and (2) were included.

The mean correct RTs, standard deviations ( $S D s$ ), and percentage errors for each condition, for subjects, are given in Table 1 (the data for nonobject trials in the object decision task were not analyzed). Figure 2 shows structurally similar minus structurally dissimilar scores for each condition with the associated confidence interval. For both this and the following experiment, confidence intervals were constructed by using these difference scores for each subject, which were entered into an analysis of variance (ANOVA) in order to obtain a mean

Table 1

Mean Reaction Times (in Milliseconds), Percentage Errors (PE), Standard Deviations (SDs), and Least Squares Means (LSM), for Experiment 1: Naming and Object Decision (OD) Tasks

\begin{tabular}{|c|c|c|c|c|c|c|c|c|}
\hline \multirow[b]{2}{*}{ Category } & \multicolumn{4}{|c|}{$\begin{array}{c}\text { Group 1 } \\
\text { Naming Then OD }\end{array}$} & \multicolumn{4}{|c|}{$\begin{array}{c}\text { Group } 2 \\
\text { OD Then Naming }\end{array}$} \\
\hline & $M$ & PE & $S D$ & LSM & $M$ & $\mathrm{PE}$ & $S D$ & LSM \\
\hline \multicolumn{9}{|c|}{ Naming } \\
\hline Structurally dissimilar & 737 & 7.9 & 64.3 & 775 & 724 & 4.1 & 80.8 & 733 \\
\hline Structurally similar & 1,038 & 14.2 & 157 & 974 & 970 & 10.9 & 84.6 & 886 \\
\hline \multicolumn{9}{|c|}{ Object Decision } \\
\hline Structurally dissimilar & 597 & 7.7 & 77.8 & 596 & 600 & 5.9 & 70.1 & 600 \\
\hline Structurally similar & 641 & 9.2 & 115.6 & 642 & 644 & 11.2 & 92.9 & 642 \\
\hline
\end{tabular}




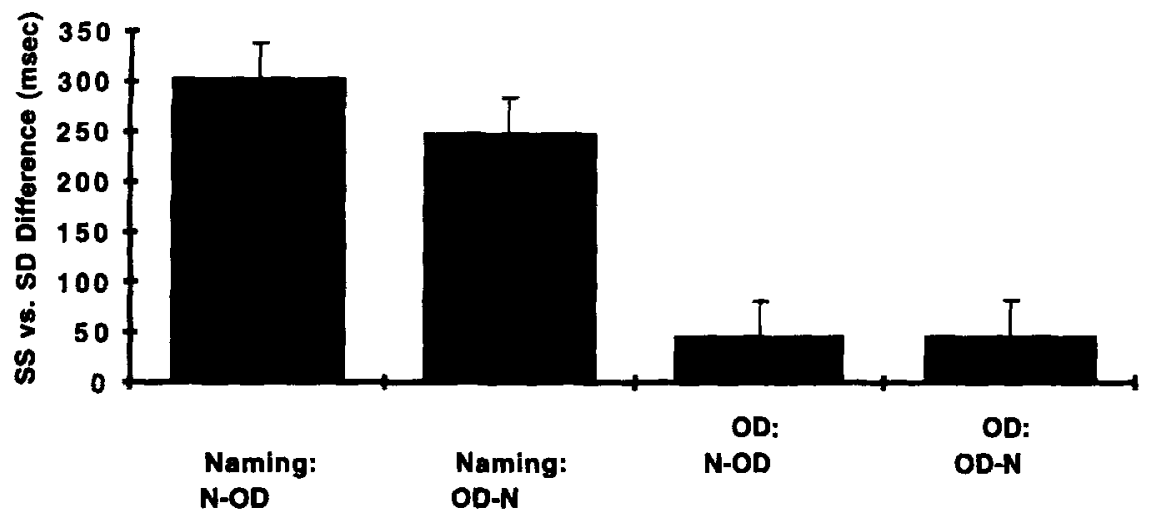

Figure 2. Task order and task for Experiment 1.

square error value, which in turn was used as the basis for the confidence interval (see Loftus \& Masson, 1994, for further details). The level of confidence was $95 \%$.

The results for both by-subjects and by-items analyses are reported. For by-subjects analyses $\left(F_{1}\right)$, the data were pooled for each subject over the various pictures presented in each combination of task order $X$ task $X$ category condition. For by-items analyses $\left(F_{2}\right)$, the data in each condition were pooled for each picture over the various subjects who were presented with that picture in that condition. $F$ values, degrees of freedom $(d f)$, and mean square error values $\left(M S_{\mathrm{e}}\right)$ for the significant main effects and interactions are given in Table 2.

For the sake of clarity and simplicity, analyses were collapsed over fruit and vegetable items on the one hand and clothing and furniture items on the other. Thus all analyses compare differences between structurally similar items (fruit and vegetables) and structurally dissimilar items (clothing and furniture).
For both Experiment 1 and Experiment 2, analyses of covariance (ANCOVAs) were also carried out on RT and (for Experiment 2) relative priming effect (RPE) data, to establish that the main effects and interactions found were not due to preexisting differences between the categories. Previous studies of object naming have suggested effects of name frequency, prototypicality, and familiarity (Humphreys et al., 1988; Oldfield \& Wingfield, 1965; Riddoch \& Humphreys, 1987b). The ANCOVAs were conducted with these three variables as covariates. We give the adjusted means in Table 1 (i.e., the means that result when the effects of the covariates have been statistically partialled out-the least squares means). Full ANCOVA statistics are given in Appendix C. It is important to note that in all cases, when the effects of the covariates are partialled out, the strong relationship between task and category remains.

Error analyses (using arcsine transformed error data) are not reported, since in all cases either there were no

Table 2

Experiment 1: $F$ Values, Degrees of Freedom $(d f)$, and Mean Square Error $\left(M S_{\mathrm{e}}\right)$ for Significant Main Effects and Interactions, by Subjects and by Items

\begin{tabular}{|c|c|c|c|c|c|c|}
\hline \multirow[b]{2}{*}{ Effect/Interaction } & \multicolumn{3}{|c|}{ By Subjects } & \multicolumn{3}{|c|}{ By Items } \\
\hline & $F$ & $d f$ & $M S_{\mathrm{e}}$ & $F$ & $d f$ & $M S_{\mathrm{e}}$ \\
\hline \multicolumn{7}{|c|}{ ANOVA } \\
\hline Task order & n.s. & n.s. & n.s. & n.s. & n.s. & n.s. \\
\hline Task & 190 & 1,28 & 9,615 & 267 & 1,70 & 13,344 \\
\hline Category & 286 & 1,28 & 2,649 & 82 & 1,70 & 16,103 \\
\hline Task order $\times$ task & n.s. & n.s. & n.s. & 18 & 1,70 & 4,059 \\
\hline Task order $\times$ category & n.s. & n.s. & n.s. & 6 & 1,70 & 4,292 \\
\hline Task $\times$ category & 158 & 1,28 & 2,506 & 45 & 1,70 & 13,344 \\
\hline Task order $\times$ task $\times$ category & n.s. & n.s. & n.s. & 6 & 1,70 & 4,059 \\
\hline \multicolumn{7}{|c|}{ Further ANOVA } \\
\hline \multicolumn{7}{|l|}{ Naming then object decision } \\
\hline Task & & & & 198 & 1,70 & 11,805 \\
\hline Category & & & & 68 & 1,70 & 12,635 \\
\hline Task $\times$ category & & & & 37 & 1,70 & 11,805 \\
\hline \multicolumn{7}{|l|}{ Object decision then naming } \\
\hline Task & & & & 233 & 1,70 & 5,599 \\
\hline Category & & & & 63 & 1,70 & 7,760 \\
\hline Task $\times$ category & & & & 33 & 1,70 & 5,599 \\
\hline
\end{tabular}


main effects or interactions, or the same pattern emerged as for RTs. There was no evidence for a tradeoff between speed and accuracy.

A three-way mixed design ANOVA was carried out. The factors were task order (naming then object decision vs. object decision then naming), task (naming vs. object decision), and category (structurally similar vs. structurally dissimilar). This same analysis was carried out on RT and error data (arcsine transformed).

There was a significant main effect of task $\left[F_{1}(1,28)=\right.$ $189.60, M S_{\mathrm{e}}=9,615, p<.0001 ; F_{2}(1,70)=267.08$, $\left.M S_{\mathrm{e}}=13,344, p<.0001\right]$ and of category $\left[F_{1}(1,28)=\right.$ $286.08, M S_{\mathrm{e}}=2,649, p<.0001 ; F_{2}(1,70)=82.13, M S_{\mathrm{e}}=$ $16,103, p<.0001]$, and a significant category $\times$ task interaction $\left[F_{1}(1,28)=158.09, M S_{\mathrm{e}}=2,506, p<.0001\right.$; $\left.F_{2}(1,70)=44.6, M S_{\mathrm{e}}=13,344, p<.0001\right]$. By items only, there was a significant task order $\times$ category interaction $\left[F_{1}(1,28)=2.11, F_{2}(1,70)=5.84, M S_{\mathrm{e}}=4,292, p<.05\right]$, a significant task order $\times$ task interaction $\left[F_{1}(1,28)=\right.$ $\left.1.43, F_{2}(1,70)=18.29, M S_{\mathrm{e}}=4,059, p<.0001\right]$, and a significant task $\times$ category $\times$ task order interaction $\left[F_{1}(1,28)=2.27, F_{2}(1,70)=6.54, M S_{\mathrm{e}}=4,059, p<.05\right]$. No other main effects or interactions were significant.

Further analysis of the task $\times$ category interaction using planned comparisons showed a significant difference between structurally similar and structurally dissimilar items for both tasks ( $p \mathrm{~s}<.01)$. However, the difference was substantially greater for naming ( $274 \mathrm{vs.}$ $44 \mathrm{msec}$ for naming and object decision, respectively).

The three-way interaction by items was further analyzed by carrying out separate ANOVAs for each task order group. For the naming then object decision group, there was a main effect of task $\left[F_{2}(1,70)=197.69, M S_{\mathrm{e}}=\right.$ $11,805, p<.0001]$ and of category $\left[F_{2}(1,70)=67.74\right.$, $\left.M S_{\mathrm{e}}=12,635, p<.0001\right]$ and a task $\times$ category interaction $\left[F_{2}(1,70)=36.99, M S_{\mathrm{e}}=11,805, p<.0001\right]$. For the object decision then naming group, the same results were found: there was a main effect of task $\left[F_{2}(1,70)=\right.$ $\left.233.01, M S_{\mathrm{e}}=5,599, p<.0001\right]$ and of category $\left[F_{2}(1,70)\right.$ $\left.=63.36, M S_{\mathrm{e}}=7,760, p<.0001\right]$, and a task $\times$ category interaction $\left[F_{2}(1,70)=33.06, M S_{\mathrm{e}}=5,599, p<.0001\right]$.

For both the object decision then naming and the naming then object decision groups, category effects were larger on naming than on object decision (a maximum contrast of $301 \mathrm{msec}$, across the categories for naming, relative to a contrast of $44 \mathrm{msec}$, for object decision). The three-way task $\times$ category $\times$ task order interaction arose because for structurally similar items, naming was facilitated by subjects' having earlier performed an object decision task, relative to when they named the stimuli first (for structurally dissimilar items, naming RTs were 737 and $724 \mathrm{msec}$, for naming first and naming preceded by object decision, respectively; for structurally similar items, naming RTs were 1,038 and $970 \mathrm{msec}$, for naming first and naming preceded by object decision, respectively).

\section{Discussion}

The main findings were as follows. There were longer RTs to vegetables and fruit than to clothing and furni- ture. Further, this category difference was greater for naming than for object decision. These effects cannot be attributed to preexisting differences between the categories in terms of name frequency, prototypicality, or familiarity. The error data and item analyses argue against the RT difference's being due to relatively low name agreement (i.e., with longer RTs for items with low name agreement). First, were this the case, we would expect more errors to vegetables and fruit than to clothing and furniture. In fact there was no significant difference in the number of errors to objects from these categories for naming, where such an effect would be expected to manifest itself. In addition, we might also have expected the longer RTs to fruit and vegetables than to clothing and furniture only to be true for a subset of items with low name agreement, since many objects from these categories have high name agreement. However, the item analyses confirmed that the results were true for the majority of objects, not just a subset. ${ }^{2}$

The results confirm that category effects can arise in normal visual object recognition and that they are not solely characteristic of a damaged recognition system (see also Humphreys et al., 1988). In addition, the data demonstrate that the effects with normal subjects are greater on naming than on object decision. This finding could arise because either semantic or name information, which may be required for naming but not object decision, is more difficult to retrieve for fruit and vegetables than for clothing and furniture. Evidence that object decision tasks need not require access to either semantic or name information comes from the neurological literature, where patients have been shown to retain good performance on difficult object decision tests despite having marked impairments in their ability either to name or to retrieve associative information about objects (Chertkow, Bub, \& Caplan, 1992; Riddoch \& Humphreys, 1987a; Sheridan \& Humphreys, 1993). Converging support, with normal observers, comes from Lupker (1988), who failed to find any semantic priming of object decision with a sequential presentation paradigm (as used here). Furthermore, as we have noted above, the present category effects cannot easily be attributed to differences in familiarity, prototypicality, or name frequency across the stimulus sets-factors that likely influence semantic and name retrieval. It should be noted, however, that Kroll (1990) did find sentence priming effects on simultaneous object decision (we will discuss this issue further following Experiment 2).

Lloyd-Jones and Humphreys (1996) found that times to articulate printed versions of the names of the stimuli used in Experiment 1 did not differ, which is consistent with naming times per se being equal across the category members. Lloyd-Jones (1992) did find some evidence for slower categorization of vegetables than of clothing and furniture when the stimuli were presented as words (in a categorization task requiring discriminations between (1) fruit and vegetables or (2) clothing and furniture), suggesting that semantic retrieval may be difficult for vegetables. Nevertheless, the size of this effect was 
considerably smaller than the category effect on naming in Experiment 1; also the names of fruit were categorized as efficiently as the names of clothing and furniture, yet here fruit were still considerably more difficult to name when presented pictorially. These last results indicate that neither semantic nor name retrieval per se is markedly more difficult for fruit and vegetables than for clothing and furniture (though see Job, Rumiati, \& Lotto, 1992); rather, the difficulty seems pronounced only with visual object processing: semantic and name retrieval for fruit and vegetables is difficult primarily when objects are presented visually. This fits with the idea that individual fruit and vegetables, sharing perceptual neighbors, precipitate competition during the stages of semantic and name retrieval, slowing their naming more than the naming of objects with fewer perceptual neighbors (clothing and furniture). Note also that category effects were smaller on object decision than on naming. From this it seems that the main consequence of having multiple perceptual neighbors is to generate competition at semantic and name retrieval stages of object processing, rather than to slow access to structural knowledge itself (as required for the difficult object decision task used here).

Experiment 1 also indicated that, for structurally similar items, naming times were faster when subjects had earlier made object decisions to the same stimuli relative to when they named the stimuli without seeing them earlier (gains were $68 \mathrm{msec}$ for structurally similar items, and $13 \mathrm{msec}$ for structurally dissimilar items). Apparently there was differential priming for the naming of structurally similar items following earlier object decision performance. This suggests that the preactivation of stored structural knowledge required for object decision helped reduce subsequent competition in either semantic or name retrieval. We explored this further in Experiment 2.

\section{EXPERIMENT 2}

In Experiment 2, we looked at the effects of priming in more detail. The cascade model makes several predictions concerning the effects on subjects' performance when object decision or naming is primed by the same stimuli's having been encountered earlier in either the same or the other task. First, priming should reduce competition and hence benefit performance (in terms of reducing RT and increasing accuracy), in both tasks. We are proposing that object decision in one sense is closer to naming than it is to categorization. For superordinate categorization (e.g., living vs. nonliving), for example, subjects do not need to differentiate between competing representations in order to perform the task successfully. The activation of many perceptually similar exemplars aids superordinate categorization, and that is why it is faster for structurally similar objects (e.g., Lloyd-Jones \& Humphreys, 1996; Price \& Humphreys, 1989). In contrast, to distinguish, for example, a leek from a leek/ broccoli nonobject in object decision (see Appendix A) requires access to information specific to the target ob- ject; information specific to the general category of the stimuli (i.e., vegetable) is not sufficient. The same is true for naming, and thus both tasks require differentiation between competing exemplars, leading to longer RTs for perceptually similar items in both tasks. Nevertheless, the differentiation required for naming is greater than that for object decision, because in the former case a unique label has to be retrieved. Hence the RT difference between perceptually similar and dissimilar items will be greater for naming. It follows from this that as competition is greater for naming, priming effects should be stronger on naming than on object decision (as the target task). Similarly, because competition is greater for objects that are perceptually similar, this class of object should benefit more from priming.

A further prediction follows if slowed naming of fruits and vegetables arises as a consequence of greater interitem perceptual similarity. Preactivating stored structural knowledge in object decision should reduce category effects in naming to the same extent as preactivating stored structural, semantic, and phonological knowledge (as occurs in naming): we expect priming effects from object decision and naming to be equivalent on naming as the target task. Of course, competition at semantic and name levels may also be selectively increased for fruits and vegetables, and this may only be reduced by prior naming. In this case, object decision will prime naming, but not as effectively as naming itself.

It might be noted that in Experiment 1 we found neither priming from naming onto object decision, nor priming for structurally dissimilar items. However, with a more sensitive experimental design involving shorter intertask intervals, within-subject unprimed baselines, and more items, these effects might become apparent. The differential priming effects on the different categories and tasks were assessed in detail in Experiment 2, in which we orthogonally manipulated object decision and naming as prime and target tasks. This contrast enabled us to assess the effects of within-task priming (e.g., object decision-object decision) as well as across-task priming (e.g., naming-object decision). Any priming effects specific to the task should be greater in within-than across-task priming (cf. Jacoby, 1983; Monsell, 1985).

Subjects first received a block of primes, and these were immediately followed by a "target" block, half of which had been encountered in the prime block, and half of which had not. We rotated item presentation so that, without repetition for any one subject, across the experiment as a whole the same items served as primes, primed targets, and unprimed targets. The unprimed baseline condition (in which stimuli presented in a "target" block had not been preceded by primes) enabled us to assess priming effects uncontaminated by practice.

\section{Method}

Subjects. There were 64 subjects (male and female). All were paid members of the Birkbeck College subject pool, and all had normal or corrected-to-normal vision. Further, ali were native En- 
glish speakers and had not seen the pictures before. Each subject participated in a single experimental session lasting about $40 \mathrm{~min}$.

Design, Procedure, Stimuli, and Apparatus. The variables of prime task (naming vs. object decision), target task (naming vs. object decision), and category (structurally similar vs. structurally dissimilar) were examined in four conditions manipulating prime and target task: (1) naming prime task, naming target task, (2) naming prime task, object decision target task, (3) object decision prime task, naming target task, (4) object decision prime task, object decision target task.

To operationalize the experimental design and to ensure sufficient numbers of items per condition, the original set of drawings of objects used in Experiment 1 were supplemented with a further 24 , six each from the same four categories, using the same method and criteria as before. The 24 items from each category were divided into two equal lists ( $A$ and $B$ ) of 12 , pairwise matched (across means and ranges), in terms of name frequency (NF) and prototypicality (P), using the Francis and Kucera (1982) and Rosch (1975) norms, respectively. The means were as follows: clothing, $\mathrm{A}=16.6, \mathrm{~B}=16.9(\mathrm{NF})$, and $\mathrm{A}=3, \mathrm{~B}=3(\mathrm{P})$; furniture, $\mathrm{A}=30.7, \mathrm{~B}=28.4(\mathrm{NF})$, and $\mathrm{A}=4, \mathrm{~B}=4(\mathrm{P})$; fruit, $\mathrm{A}=$ $3.9, \mathrm{~B}=2.9$ (NF; this relatively large mean difference was caused by one item only-namely, lemon), and $\mathrm{A}=2.3, \mathrm{~B}=2.8(\mathrm{P})$; vegetables, $\mathrm{A}=5.5, \mathrm{~B}=5.3(\mathrm{NF})$, and $\mathrm{A}=2.4, \mathrm{~B}=3.1(\mathrm{P})$.

The extra items are listed in Appendix D. The stimuli were presented as in Experiment 1, on a two-field tachistoscope, and RTs (in milliseconds) were recorded with a Birkbeck digital timer.

For each condition, half of the 16 subjects received List $A$ of each category as the prime block (randomly ordered, with the constraint that each stimulus was not preceded by the same category on the previous 2 trials, to reduce intertrial priming) with Lists $A$ and $\mathrm{B}$ as the target block. The other half received List $\mathrm{B}$ as the prime block and Lists A and B as the target block. Thus, for each group of subjects, half the targets were primed and half were unprimed. Each block lasted 15-20 min, and the second block followed the first immediately. For the naming task, there were 20 practice trials: 48 experimental trials in the prime block and 96 trials in the target block. For the object decision task, there were 20 practice trials: 96 experimental trials in the prime block and 192 trials in the target block. Practice was prior to both tasks (i.e., not in the intertask interval). Thus, the repetition lag for each condition was different: (1) For naming then object decision, the lag could be a minimum of 1 trial and a maximum of 240 trials. (2) For object decision then naming, the lag could be a minimum of 1 trial and a maximum of 192 trials. (3) For naming then naming, the lag could be a minimum of 1 trial and a maximum of 144 trials. (4) For object decision then object decision, the lag could be a minimum of 1 trial and a maximum of 288 trials. ${ }^{3}$ Practice stimuli came from categories other than those used in the experimental trials, and were presented prior to the presentation of prime and target experimental blocks. Stimuli were presented until subjects responded.

\section{Results}

Mean correct RTs and errors were collated for each condition. Error criteria were the same as in Experiment 1. In addition, responses to target trials on which an error had been made to the picture on the corresponding prime trial were not excluded. This was because the exclusion of such data may have resulted in the removal of items that were intrinsically more "difficult" to respond to; since data from such an item would be excluded from the primed but not the unprimed conditions, a false priming effect might have resulted. Further, feedback would have involved inappropriate priming. Thus, to include such data seemed the most conservative approach (see Wheeldon \& Monsell, 1992, for a discussion of this point).

Analyses were carried out both on the difference between primed target task scores and the appropriate unprimed baseline target task scores (the "relative priming effect": RPE), and on baselines alone (i.e., on targets not presented during the prime task phase of the experiment). These analyses were carried out (1) to examine whether there were category differences in the degree of priming that results from a prior encounter with the stimulus, and (2) to ensure that any effects were due to priming and not a shift in baseline from one condition to another.

In addition, primed RTs were analyzed to examine whether the RPE (equivalent for both object decision and naming prime tasks) was due to the fact that performance was at ceiling. This was not the case (full statistical analyses are given in Appendix E).

Consistent with Experiment 1, analyses were collapsed over fruit and vegetable items on the one hand and clothing and furniture items on the other to compare differences between structurally similar items (fruit and vegetables) and structurally dissimilar items (clothing and furniture). Error analyses (using arcsine transformed error data) are not reported for RPE and baseline data, because in all cases either there were no main effects or interactions, or the same pattern emerged as for RTs. There was no evidence for a tradeoff between speed and accuracy. The mean correct RTs, standard deviations $(S D s)$, and percentage errors for each condition (in brackets), for subjects, for the RPE, baselines, and primed RTs are given in Table 3. Least mean squares from the ANCOVA for the RPE and baseline scores are also given. $F$ values, degrees of freedom $(d f)$, and mean square error values $\left(M S_{\mathrm{e}}\right)$ for the significant main effects and interactions are given in Table 4. Figures 3, 4, and 5 show structurally similar minus structurally dissimilar scores with associated confidence intervals for each condition for RPE, baseline, and primed RT effects. As with Experiment 1, confidence intervals were constructed using these difference scores for each subject, which were entered into an ANOVA in order to obtain a mean square error value which in turn was used as the basis for the confidence interval (see Loftus \& Masson, 1994, for further details). The level of confidence was $95 \%$.

General priming effects for each task were also analyzed (i.e., primed vs. unprimed target task scores averaged over categories). These analyses tell us whether there were differential priming effects across task, regardless of the category of object.

Finally, ANCOVAs were also carried out; they are given in Appendix C. Note that, as with Experiment 1, the following results are unaltered by including familiarity, prototypicality, and name frequency as covariates.

RPE: RT data. A three-way mixed ANOVA was carried out over all eight conditions. The factors were prime task (naming vs. object decision), target task (naming vs, object decision), and category (structurally similar vs. 
Table 3

Mean Reaction Times (in Milliseconds), Percentage Errors (PE), Standard Deviations (SDs), and Least Squares Means (LSM) for Baselines, Primed RTs, and Relative Priming Effect (RPE) in Experiment 2: Naming and Object Decision (OD) Tasks

\begin{tabular}{|c|c|c|c|c|c|c|c|c|c|c|c|c|c|c|c|c|}
\hline \multirow[b]{3}{*}{ Category } & \multicolumn{16}{|c|}{ Prime and Target Task Condition } \\
\hline & \multicolumn{4}{|c|}{ Naming-Naming } & \multicolumn{4}{|c|}{ Naming-OD } & \multicolumn{4}{|c|}{ OD-Naming } & \multicolumn{4}{|c|}{$\mathrm{OD}-\mathrm{OD}$} \\
\hline & $M$ & $\mathrm{PE}$ & $S D$ & LSM & $M$ & PE & $S D$ & LSM & $M$ & PE & $S D$ & LSM & $M$ & $\underline{P E}$ & $S D$ & LSM \\
\hline \multicolumn{17}{|c|}{ Baseline } \\
\hline Structurally dissimilar & 805 & 3.5 & 94.3 & 805 & 662 & 5.9 & 81.4 & 648 & 756 & 8.2 & 64.9 & 806 & 635 & 5.6 & 78.9 & 630 \\
\hline Structurally similar & 1,213 & 18.1 & 174.4 & 1,150 & 712 & 12.7 & 125.5 & 717 & 1,185 & 14.7 & 205 & 1,137 & 654 & 13.5 & 112.7 & 669 \\
\hline \multicolumn{17}{|c|}{ Primed } \\
\hline Structurally dissimilar & 743 & 7.3 & 88.3 & & 629 & 6.1 & 73.7 & & 737 & 5.5 & 84.7 & & 613 & 4.9 & 70.1 & \\
\hline Structurally similar & 1,040 & 16 & 195.2 & & 671 & 9.1 & 74.7 & & 1,090 & 11.5 & 94.6 & & 640 & 10.1 & 86.7 & \\
\hline \multicolumn{17}{|c|}{ RPE } \\
\hline Structurally dissimilar & 62 & -3.9 & 50.1 & 44 & 33 & -0.15 & 16.6 & 19 & 19 & 2.7 & 71.5 & 34 & 22 & 0.7 & 24.5 & 20 \\
\hline Structurally similar & 173 & 2.1 & 211.8 & 157 & 41 & 1 & 65.4 & 43 & 95 & 3.4 & 220.6 & 118 & 14 & 3.5 & 50.7 & 25 \\
\hline
\end{tabular}

structurally dissimilar). This same analysis was carried out on RPE, baseline, and primed data, for both RTs and errors (arcsine transformed).

There was a significant main effect of prime task by subjects only, with greater priming for the naming task $\left[F_{1}(1,60)=4.62, M S_{\mathrm{e}}=10,976, p<.05\right]$. There was a significant main effect of target task, with priming greater on the naming task $\left[F_{1}(1,60)=10.44, M S_{\mathrm{e}}=10,976\right.$, $\left.p<.005 ; F_{2}(1,94)=22.24, M S_{\mathrm{e}}=14,434, p<.0001\right]$. Further, there was a main effect of category $\left[F_{1}(1,60)=\right.$ $4.19, M S_{\mathrm{e}}=16,256, p<.05 ; F_{2}(1,94)=17.36, M S_{\mathrm{e}}=$ $20,158, p<.0001]$. Finally, there was a target task $\times$ cat-

Table 4

Experiment 2: $F$ Values, Degrees of Freedom ( $d f$ ), and Mean Square Error $\left(M S_{\mathrm{e}}\right)$ for Significant Main Effects and Interactions, by Subjects and by Items

\begin{tabular}{|c|c|c|c|c|c|c|}
\hline \multirow[b]{2}{*}{ Effect/Interaction } & \multicolumn{3}{|c|}{ By Subjects } & \multicolumn{3}{|c|}{ By ltems } \\
\hline & $F$ & df & $M S_{\underline{\mathrm{e}}}$ & $F$ & $d f$ & $M S_{\mathrm{c}}$ \\
\hline \multicolumn{7}{|c|}{ Relative Priming Effect } \\
\hline Prime task & 5 & 1,60 & 10,976 & n.s. & n.s. & n.s. \\
\hline Target task & 10 & 1,60 & 10,976 & 22 & 1,94 & 14,434 \\
\hline Category & 4 & 1,60 & 16,256 & 17 & 1,94 & 20,158 \\
\hline Prime task $\times$ target task & 1 (n.s.) & 1,60 & 10,976 & .05 (n.s.) & 1,94 & 15,640 \\
\hline Prime task $\times$ category & n.s. & n.s. & n.s. & n.s. & n.s. & n.s. \\
\hline Target task $\times$ category & 4 & 1,60 & 16,256 & 18 & 1,94 & 14,434 \\
\hline Prime task $\times$ target task $\times$ category & $<1$ & n.s. & n.s. & $<1$ & n.s. & n.s. \\
\hline \multicolumn{7}{|c|}{ Baselines } \\
\hline Prime task & n.s. & n.s. & n.s. & 4 & 1,94 & 9,862 \\
\hline Target task & 151 & 1,60 & 22,205 & 400 & 1,94 & 22,844 \\
\hline Category & 172 & 1,60 & 9,523 & 154 & 1,94 & 32,092 \\
\hline Prime task $\times$ target task & n.s. & n.s. & n.s. & n.s. & n.s. & n.s. \\
\hline Prime task $\times$ category & n.s. & n.s. & n.s. & n.s. & n.s. & n.s. \\
\hline Target task $\times$ category & 124 & 1,60 & 9,523 & 142 & 1,94 & 22,844 \\
\hline Prime task $\times$ target task $\times$ category & n.s. & n.s. & n.s. & n.s. & n.s. & n.s. \\
\hline \multicolumn{7}{|c|}{ Primed } \\
\hline Prime task & n.s. & n.s. & n.s. & n.s. & n.s. & n.s. \\
\hline Target task & 137 & 1,60 & 16,311 & 428 & 1,94 & 13,922 \\
\hline Category & 205 & 1,60 & 5,071 & 127 & 1,94 & 20,403 \\
\hline Prime task $\times$ target task & n.s. & n.s. & n.s. & 5 & 1,94 & 7,261 \\
\hline Prime task $\times$ category & n.s. & n.s. & n.s. & n.s. & n.s. & n.s. \\
\hline Target task $\times$ category & 133 & 1,60 & 5,071 & 114 & 1,94 & 13,992 \\
\hline Prime task $\times$ target task $\times$ category & 2 (n.s.) & n.s. & n.s. & 2 (n.s.) & n.s. & n.s. \\
\hline \multicolumn{7}{|c|}{ General Priming } \\
\hline Prime task & n.s. & n.s. & n.s. & n.s. & n.s. & n.s. \\
\hline Target task & 167 & 1,60 & 16,513 & 226 & 1,95 & 66,358 \\
\hline Priming & 38 & 1,60 & 2,745 & 22 & 1,95 & 28,344 \\
\hline Prime task $\times$ target task & n.s. & n.s. & n.s. & n.s. & n.s. & n.s. \\
\hline Prime task $\times$ priming & n.s. & n.s. & n.s. & n.s. & n.s. & n.s. \\
\hline Target task $\times$ priming & 10 & 1,60 & 2,745 & 8 & 1,95 & 20,902 \\
\hline Prime task $\times$ target task $\times$ priming & 1 (n.s.) & n.s. & n.s. & $<1$ (n.s.) & n.s. & n.s. \\
\hline
\end{tabular}




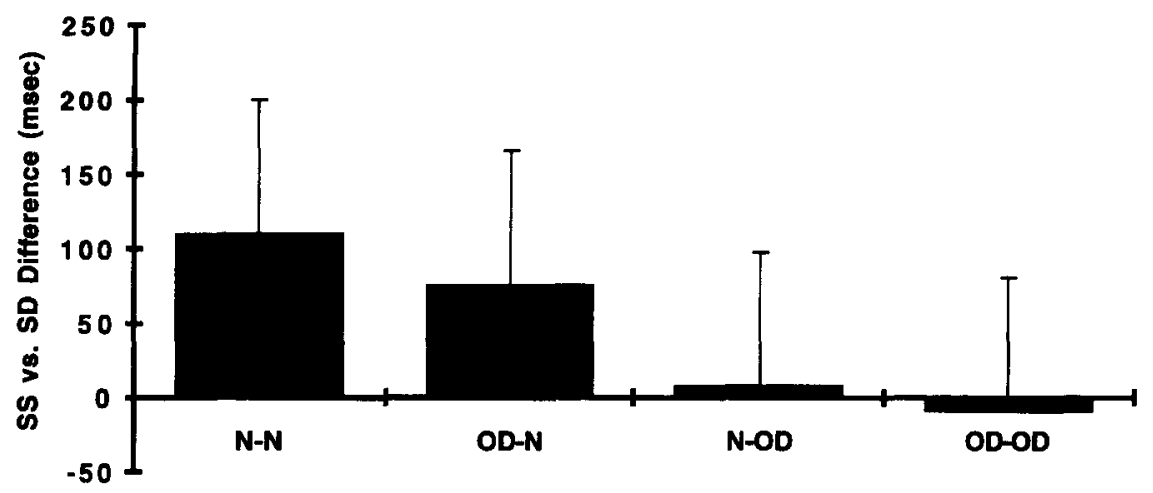

Figure 3. Confidence intervals: Experiment 2 relative priming effect.

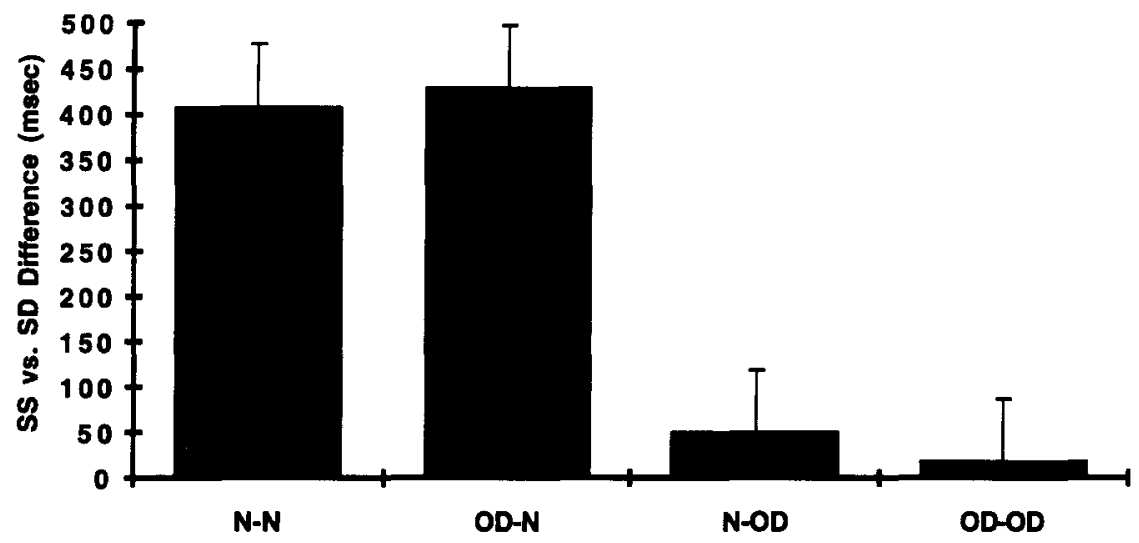

Figure 4. Confidence intervals: Experiment 2 baselines.

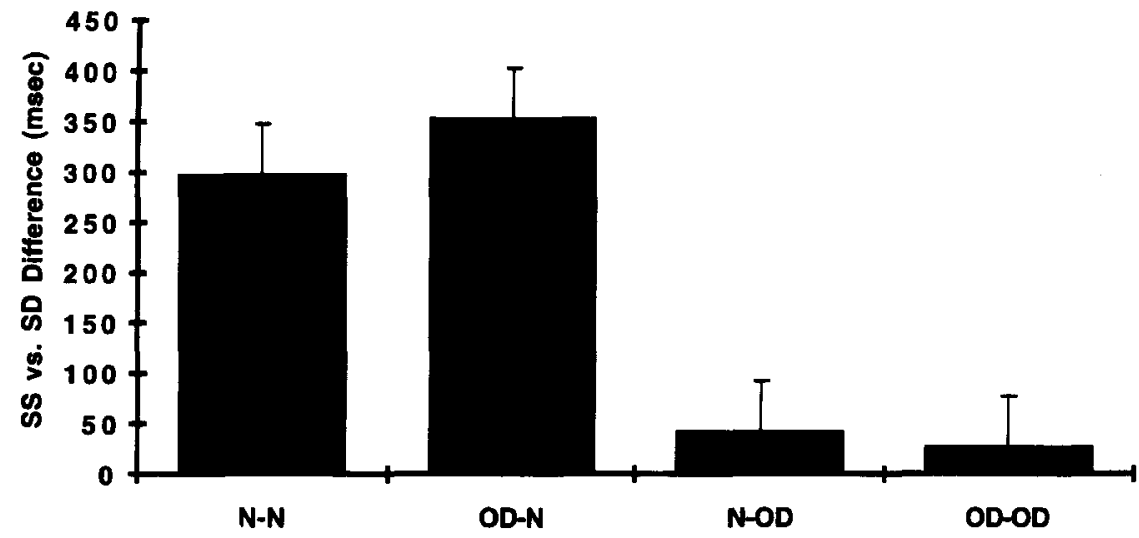

Figure 5. Confidence intervals: Experiment 2 primed.

egory interaction $\left[F_{1}(1,60)=4.31, M S_{\mathrm{e}}=16,256\right.$, $\left.p<.05 ; F_{2}(1,94)=18.41, M S_{\mathrm{e}}=14,434, p<.0001\right]$. No other main effects or interactions were significant (including the three-way interaction, $F_{1}<1, F_{2}<1$ ).

Further analysis of the target task $\times$ category interaction using planned comparisons showed that for the naming task there was greater priming for structurally similar items compared with structurally dissimilar items $(p s<.01)$. There was no category difference for object decision. Note that the target task $\times$ category interaction was not qualified by the prime task. Greater priming occurred on naming than on object decision, and on struc- 
turally similar items relative to structurally dissimilar items, regardless of whether subjects made object decisions to or named the primes.

Baselines: RT data. There was a significant main effect of target task $\left[F_{1}(1,60)=151.28, M S_{\mathrm{e}}=22,205\right.$, $p<.0001 ; F_{2}(1,94)=400.34, M S_{\mathrm{e}}=22,844, p<$ $.0001]$. Naming times were slower than object decision times. There was a significant main effect of category $\left[F_{1}(1,60)=172.11, M S_{\mathrm{e}}=9,523, p<.0001 ; F_{2}(1,94)=\right.$ $\left.154.24, M S_{\mathrm{e}}=32,092, p<.0001\right]$. Finally, there was a significant target task $\times$ category interaction $\left[F_{1}(1,60)=\right.$ $123.96, M S_{\mathrm{e}}=9,523, p<.0001 ; F_{2}(1,94)=141.66$, $\left.M S_{\mathrm{e}}=22,844, p<.0001\right]$. By items only, there was a marginally nonsignificant main effect of prime task $\left[F_{1}(1,60)=2.35 ; F_{2}(1,94)=3.74, M S_{\mathrm{e}}=9,862, p=\right.$ $.056]$. No other main effects or interactions were significant.

Further analysis of the target task $\times$ category interaction using planned comparisons showed that for naming, there were longer RTs to structurally similar compared with structurally dissimilar items $(p s<.01)$. For object decision, for the items analysis only, there were also longer RTs to structurally similar than to structurally dissimilar items $\left(t_{\text {obs }}=1.99, t_{\text {crit }}=1.67, p<.05\right)$.

General priming: RT data. A three-way mixed ANOVA was carried out over all eight conditions. The factors were prime task (naming vs. object decision), target task (naming vs. object decision), and priming (primed vs. unprimed).

There was a main effect of target task $\left[F_{1}(1,60)=\right.$ $167.59, M S_{\mathrm{e}}=16,513, p<.0001 ; F_{2}(1,95)=225.65$, $\left.M S_{\mathrm{e}}=66,357, p<.0001\right]$, with longer response times for naming. Further, there was a main effect of priming $\left[F_{1}(1,60)=38.05, M S_{\mathrm{e}}=2,745, p<.0001 ; F_{2}(1,95)=\right.$ $\left.21.92, M S_{\mathrm{e}}=28,345, p<.0001\right]$, with longer response times to unprimed stimuli. Finally, there was a target task $\times$ priming interaction $\left[F_{1}(1,60)=10.44, M S_{\mathrm{e}}=2,745\right.$, $\left.p<.005 ; F_{2}(1,95)=7.94, M S_{\mathrm{e}}=20,902, p<.01\right]$. Planned comparisons revealed significant differences in priming for both naming and object decision $(p<.01$ and $p<.05$, respectively). However, differences were greater for naming ( $88 \mathrm{msec}$ priming difference for naming vs. $28 \mathrm{msec}$ priming difference for object decision).

\section{Discussion}

The results were as follows:

1. The unprimed baseline data replicate the findings of Experiment 1 . For the naming task, there were longer RTs to structurally similar than to structurally dissimilar objects. Note that the lack of a prime task $\times$ target task interaction for the baseline data verifies that the priming effects are real, and not due to a shift in baseline from one condition to another. For object decision, the results were not quite so robust; nevertheless, category differences (with longer RTs to structurally similar objects than to structurally dissimilar objects), albeit much smaller, were found for primed RTs, the items analysis of baseline data, and the adjusted means in the ANCOVA. They did not, however, emerge in the RPE analysis or the by-subjects baseline analysis. With greater experimental and (hence) statistical power we would expect these relatively small RT category differences to emerge as significant more consistently across analyses (we will discuss power problems later).

2. As predicted, there was priming for both naming and object decision as target tasks. However, priming was much greater for naming.

3. Of most interest, with both naming and object decision as prime tasks, there was greater priming for the naming of structurally similar as opposed to structurally dissimilar targets. The category priming effects on naming were not due to the covarying factors of name frequency, prototypicality, familiarity, and complexity.

4. Priming effects for naming and for object decision were equivalent from both prime tasks. For object decision (as the target task), neither object decision nor naming produced consistent category priming differences. For naming (as the target task), however, the priming effects of object decision and naming were equivalent; both produced a strong category difference. Thus, overall, the difference in priming between structurally similar and structurally dissimilar objects was the same regardless of the nature of the priming task. Analysis of RTs to the primed targets revealed that a category difference still remained for naming (with longer RTs to vegetable and fruit exemplars; see Appendix E). It follows that equivalent priming effects across the different prime tasks for naming were not simply because subjects' performance was at ceiling. It was possible for a task-specific benefit for naming structurally similar objects to emerge, but none did.

However, the equivalent category priming effect on naming may not be as clear-cut as it first appears. The confidence intervals for the RPE data (see Figure 3) show that we cannot be overly confident that the sample means provide as good an estimate of the underlying population means as they might. Thus, we should be circumspect in accepting the null hypothesis that there is no difference between object decision and naming in their effect on structurally similar and structurally dissimilar object name retrieval. Although this is correct, we note that (1) while the RPE for structurally similar objects is $173 \mathrm{msec}$ for the naming then naming condition, and only $95 \mathrm{msec}$ for the object decision then naming condition (a difference of $78 \mathrm{msec}$; see Table 3 ), which is an unreasonably large difference to accept as a null result, in fact (2) the difference in RPE between structurally similar and structurally dissimilar categories for the naming then naming condition was $111 \mathrm{msec}$, whereas the difference for the object decision then naming condition was $76 \mathrm{msec}$ (a difference between the two of only $35 \mathrm{msec}$ ). We would expect some differences between these two prime task conditions because different subjects performed under each condition, and in fact, RTs overall were slightly slower in the naming then naming condition. This equivalence across prime tasks in terms of the difference in subsequent naming of structurally similar and structurally dissimilar objects is fur- 
ther supported by examining the least squares means from the ANCOVA (see Table 3, where the difference between naming structurally similar and structurally dissimilar objects for each of the prime task conditions is also now less: $113 \mathrm{vs} .84=29 \mathrm{msec}$ ).

In sum, then, the data suggest that object decision and naming as prime tasks produce equivalent differences in priming between structurally similar and dissimilar objects for naming; the implications of this result will be discussed in some detail below. However, we must add the caveat that with greater statistical power, which both the confidence intervals and object decision data suggest is lacking, we may find a difference in priming effects from object decision and naming as prime tasks. If this should be so, we would predict category priming effects to be greater for the naming then naming condition than for the object decision then naming condition (for the reasons outlined in the introduction to Experiment 2).

Competing accounts of category differences. There are several possible accounts of these results. One is that category differences are more marked in naming than in object decision, simply because naming is the more difficult task. It would then follow that category differences are not necessarily reflected in processes specific to naming (such as individuation of semantic information for a particular object, or name retrieval); any task that is more difficult should show larger category differences. In addition, priming effects may be larger on naming than on object decision (as the target task), because prime-target intervals tended to be longer when object decision was used as the target task (owing to the use of nonobject fillers in object decision but not in naming). If these explanations are correct, conclusions concerning the priming of processes specific to naming (and sensitive to category differences) will be limited.

The grounds for rejecting these possibilities are as follows. First, Lloyd-Jones and Humphreys (1996) examined picture categorization (fruit vs. vegetable, clothing vs. furniture) in addition to picture naming. Picture categorization times (using the same objects as here) were slower than object decision times from the present paper, though naming times in the two studies were similar; in fact, for the structurally dissimilar classes of stimuli, RTs for categorization and naming times were roughly equivalent (e.g., in Experiment 1 from Lloyd-Jones \& Humphreys, 1996, RTs were 769 and $730 \mathrm{msec}$ for naming and categorization, respectively; in their Experiment 2, RTs were 789 and $766 \mathrm{msec}$, respectively). Despite categorization's being relatively difficult (and for structurally dissimilar items, being as difficult as naming), category differences were smaller in categorization than in naming (e.g., in Experiment 2 in Lloyd-Jones \& Humphreys, 1996, category effects were an average of $126 \mathrm{msec}$ for categorization and $334 \mathrm{msec}$ for naming). The size of any category effects is not directly related to the overall time taken to perform the task. Second, the magnitude of priming was not a monotonic function of the time taken to perform either the priming or the target task. LloydJones and Humphreys found that picture categorization failed to show repetition priming as a target task (despite being as difficult as naming, for structurally dissimilar items), and also that as a prime task, categorization did not facilitate target naming (unlike object decision, even though object decision is the faster task). Moreover, across three experiments (manipulating prime and target modality), baseline RTs to name structurally similar pictures did not predict the magnitude of priming (see Table 5). Third, the prime-target interval was identical for naming and categorization in Lloyd-Jones and Humphreys (and shorter than when object decision was the priming task and naming the target task, as here, when priming was observed), yet priming occurred only for the naming task. Furthermore, even from the present data it is apparent that the lag between primes and targets is not critical. In the object decision then naming condition, primes and targets were separated by an average of 48 trials more than in the naming then naming condition, yet priming effects were equally strong. In the naming then object decision condition, there was again an average increase of 48 trials relative to the naming then naming condition, but now priming was absent. We conclude that neither the time between primes and targets nor the overall time to perform the task is critical for either category effects or robust priming effects to emerge on picture naming. More important, we believe, are the processes engaged in by primes and targets and required in order for the task to be performed.

There was also no evidence for within-task priming generally being greater than across-task priming. This shows that priming was not due to subjects' carrying over task-specific episodic memories from the prime task (cf. Jacoby, 1983; Monsell, 1985). It also suggests that the extra priming effects on naming were not solely due to processes specific to naming (e.g., semantic and name retrieval). Had that been the case, naming should have been substantially more effective than object decision as the prime task; it was not.

The most straightforward account of this result is that priming is due to primes and targets activating a common representation shared by the object decision and naming tasks, the main candidate being a stored structural representation (e.g., Humphreys et al., 1988; Riddoch \& Humphreys, 1987a). According to this account,

Table 5

Mean Reaction Times (RTs) and Magnitudes of Relative Priming Effects (RPE) in Lloyd-Jones and Humphreys (1996)

\begin{tabular}{lcr}
\multicolumn{1}{c}{ Experiment } & $\begin{array}{c}\text { Picture } \\
\text { Naming RTs }\end{array}$ & RPE \\
\hline 1: Prime and Target Naming & & \\
Picture prime-picture target & 1,174 & 190 \\
$\quad$ Word prime-picture target & 1,172 & 178 \\
2: Prime Categorization, Target Naming & & \\
$\quad$ Word prime-picture target & 1,182 & 107 \\
Picture prime-picture target & 1,065 & 2 \\
2A: Prime Categorization, Target Naming & & \\
$\quad$ Word prime-picture target & 1,214 & 59 \\
\hline
\end{tabular}

Note-The prime task was either categorization or naming and the target task was naming. 
activation of a stored structural representation for an object facilitates the subsequent retrieval of semantic and name information when the object is re-presented. Since there is a benefit for retrieving semantic and name information, priming is stronger on naming than on object decision as the target task (because semantic and name retrieval are involved in naming but not object decision). Note also that priming was greatest for structurally similar objects. It follows that the initial disadvantage in naming structurally similar objects is due (at least in large part) to competition encountered by the items in accessing stored structural representations. Furthermore, for a system operating in cascade, the activation of multiple perceptual neighbors will in turn lead to competition at the semantic and/or name retrieval stages, slowing the naming of items subject to such competition. Preactivating the structural representations, by priming, benefits stimuli that normally suffer the greatest competition: namely, structurally similar objects.

One other account is consistent with the equivalent priming effects from object decision and naming (as prime tasks) on naming as the target task. If subjects retrieve either semantic or name information from objects when they perform object decisions, object decision, as a prime task, could have an effect equivalent to that of naming. For such an account to be correct, semantic and name retrieval would need to take place after object decisions had been carried out; otherwise it would be difficult to explain why object decisions were faster than object naming, why object decision (as a target task) was less affected by priming, and why category effects on object decision are smaller than those on naming. In addition, in multiple regressions performed on the baseline RT data, neither name frequency nor familiarity was a significant predictor of object decision performance, though both factors were reliable for naming. ${ }^{4}$ Nevertheless, if semantic and/or name information were retrieved after object decisions had been made ("off-line semantic/name retrieval"), the nature of the priming task (object decision vs. naming) would not differentially affect performance.

It remains problematic for the "off-line" semantic/ name retrieval account that the magnitude of the priming effects was not predicted by the familiarity, prototypicality, or name frequency of the target stimuli (in the ANCOVAs). It seems likely that to a large extent these factors influence the time taken to retrieve semantic and/or name information (see, e.g., Funnell \& Sheridan, 1992; Snodgrass \& Vanderwart, 1980). As such we would expect these factors to predict the magnitude of priming, if priming were due to common activation of semantic and name representations for primes and targets. The fact that we failed to find any evidence of this is consistent with the proposal that the locus of priming is in the stored structural representations. Overall, we cannot unequivocally rule out the "off-line" semantic/ name retrieval account. Such an account is compatible with the cascade account of object naming, although if it is correct, we cannot be certain of the specific locus of the category priming effects.

General effects of the prime task. Greater priming arose from naming than from making an object decision to the prime (significant only in the subjects analysis). An episodic memory explanation is not appropriate, because we would expect to see an effect of task congruence (i.e., greater priming for the naming-naming than for the naming-object decision condition); this was not the case. An alternative explanation is that even more finely grained visual processing is required for naming than for object decision; hence, naming leads to greater priming even on object decision as the target task.

\section{GENERAL DISCUSSION}

Category-specific priming effects were apparent on naming but not object decision as the target task. The effects of category-specific priming are at a stage of processing belonging to the naming task, but not shared with the object decision task. In contrast, the relative equivalence of the priming effect on naming for both prime tasks suggests that the cause of priming may be at a stage shared by naming and object decision tasks. Such a result is consistent with a continuous processing model (see, e.g., Humphreys et al., 1988), in which a small category difference early on may produce a greater category difference at a later stage in processing. Priming benefits the naming of structurally similar objects to a greater extent than structurally dissimilar objects, because, for the former, more perceptually similar competing neighbors are initially activated. As discussed in the introduction, increased perceptual competition in turn produces increased semantic and name competition for objects from categories with many perceptually similar exemplars. Hence, there will be relatively large benefits from preactivating the correct structural representation of an exemplar that is perceptually similar to many neighbors. Such preactivation will prevent buildup of the semantic/ name competition that is responsible for large category differences evident in naming.

In contrast, a discrete stage account is unable to localize the variation in category effects on baseline RTS across tasks, at the structural level, without assuming more than a single locus to the effect. Any effects of category on access to stored structural knowledge should combine additively with variables affecting a name retrieval stage, producing constant category effects across tasks (cf. Sternberg, 1969). Nevertheless, two discrete stage accounts of the baseline $R T$ category differences are possible. One would be to assume that the locus of category differences for the object decision task was at the level of stored structural knowledge, but that differences in naming tasks depend on whether or not semantic knowledge needs to be accessed (cf. Flores d'Arcais \& Schreuder, 1987; Funnell, 1987). Alternatively, it may be proposed that for the object decision task, at the structural level, the differentiation required is relatively crude, 
requiring structural information only. In contrast, in order to focus down and retrieve the correct name, finer differentiation at the semantic level is required. Hence, more features need to be taken into consideration at more focused classification levels.

Such accounts, however, would be unable to simultaneously explain the fact that category priming effects for picture naming were similar from object decision and naming prime tasks. Tasks that tap two loci (e.g., access to structural knowledge and name retrieval, in naming) would be expected to produce more priming in comparison with tasks that tap a single locus (access to structural knowledge only, for object decision).

Finally, two potential caveats to the present results need to be discussed. First, how general are the reported findings? In the present experiments, only two categories were used for each structural similarity condition (fruit and vegetable vs. clothing and furniture). In addition, it may reasonably be argued that fruit and vegetables are not only visually but semantically more similar to each other than are clothing and furniture. As a result, semantic similarity may have contributed to, or have been wholly responsible for, the observed category differences. Shoben (1976), for example, has shown that semantic similarity between categories can be an important determinant of performance in same-different judgments (see also, e.g., Schaeffer \& Wallace, 1969). We responded to these concerns by carrying out a further experiment with more categories of object, and in which semantic similarity was not a confound. Using independent measures of contour overlap and number of partonomic features in common (see Humphreys et al., 1988; Riddoch \& Humphreys, 1987b), we constructed a set of structurally similar and structurally dissimilar objects, matched, a priori, as far as possible for familiarity, complexity, name frequency, and prototypicality. The structurally similar set consisted of items from animal, bird, fruit, insect, and vegetable categories, whereas the structurally dissimilar set consisted of items from body part, clothing, furniture, household item, jewelry, tool, toy, and vehicle categories (the full list of items is given in Appendix F). ${ }^{5}$ Using the same method, design, and procedure, 10 subjects performed the naming then naming condition of Experiment 2. Replicating Experiment 2, we found greater priming for structurally similar items than for structurally dissimilar items (204 vs. $133 \mathrm{msec}$, a difference of $71 \mathrm{msec}$ ). The multiple regression of familiarity, name frequency, prototypicality, and contour overlap on unprimed baseline RTs confirmed that contour overlap was the only significant predictor (full statistical analyses are given in Appendix F). These results suggest strongly that the results of the present experiments do generalize and are not solely due to semantic as opposed to visual similarity. The difference in priming here was smaller than that of Experiment 2 (71 vs. $111 \mathrm{msec}$ in Experiment 2), and this may have been due to semantic similarity contributing to that effect; nevertheless, a strong effect of visual similarity remains.
Humphreys et al. (1995) have recently simulated several of the main results in the literature on object naming, including aspects of those in the present paper, in an interactive activation and competition model of object naming. The model simulated within-category structural similarity by varying the similarity of input vectors presented to the model. High visual similarity between category members produced strong competition at structural, semantic, and name levels. For items with many perceptually similar neighbors, competing representations were activated that were perceptually and semantically similar to target objects. As a result, the process of accessing structural information was difficult, and the process of accessing semantic and name information progressively yet more difficult. This was the case, even though representations for individual items needed to be differentiated for both object decision and naming responses to be made. The rate-limiting effect of structural similarity of performance (producing longer RTs for naming than for object decision) is precisely that predicted from a system operating in a cascaded rather than a temporally discrete fashion.

\section{REFERENCES}

Chertkow, H., Bub, D., \& Caplan, D. (1992). Constraining theories of semantic memory processing: Evidence from dementia. Cognitive Neuropsychology, 9, 327-365.

Cooper, L. A., Schacter, D. L., Ballesteros, S., \& Moore, C. (1992). Priming and recognition of transformed three-dimensional objects: Effects of size and reflection. Journal of Experimental Psychology: Learning, Memory, \& Cognition, 18, 43-57.

Dell, G. S., \& O'Seaghdha, P. G. (1991). Mediated and convergent lexical priming in language production: A comment on Levelt et al. (1991). Psychological Review, 98, 604-614.

Ellis, A., \& Young, A. W. (1988). Human cognitive neuropsychology. Hove: Erlbaum.

FARAH, M. J., \& MCClElLAND, J. L. (1991). A computational model of semantic memory impairment: Modality specificity and emergent category specificity. Journal of Experimental Psychology: General, 120, 339-357.

Farah, M. J., McMullen, P. A., \& Meyer, M. M. (1991). Can recognition of living things be selectively impaired? Neuropsychologia, 29, 185-193.

Farah, M. J., \& Wallace, M. A. (1992). Semantically-bounded anomia: Implications for the neural implementation of naming. Neuropsychologia, 30, 609-621.

Flores D'ARCAIS, G, B., \& SChREUder, R. (1987). Semantic activation during object naming. Psychological Research, 49, 153-159.

Francis, W. N., \& KučERA, H. (1982). Computational analyses of present-day American English. Providence, RI: Brown University Press.

FunNEll, E. (1987). Object concepts and object names: Some deductions from acquired disorders of word processing. In G. W. Humphreys \& M. J. Riddoch (Eds.), Visual object processing: A cognitive neuropsychological approach (pp. 233-260). Hove: Erlbaum.

Funnell, E., \& Sheridan, J. (1992). Categories of knowledge? Unfamiliar aspects of living and nonliving things. Cognitive Neuropsychology, 9, 135-153.

Glaser, W. R. (1992). Picture naming. Cognition, 42, 61-105.

Hart, J., Bernt, R. S., \& Caramazza, A. (1985). Category-specific naming deficit following cerebral infarction. Nature, 316, 439-440.

Hillis, A. E., \& Caramazza, A. (1991). Category-specific naming and comprehension impairment: A double dissociation. Brain, 114, 2081-2094.

Humphreys, G. W., Lamote, C., \& Lloyd-Jones, T. J. (1995). An in- 
teractive activation approach to object processing: Effects of structural similarity, name frequency, and task in normality and pathology. Memory, 3, 535-586.

Humphreys, G. W., Riddoch, M. J., \& Quinlan, P. T. (1988). Cascade processes in picture identification. Cognitive Neuropsychology, 5 , $67-103$.

JACOBY, L. L. (1983). Perceptual enhancement: Persistent effects of an experience. Journal of Experimental Psychology: Learning. Memory, \& Cognition, 9, 21-38.

Job, R., Rumiati, R., \& Lorto, L. (1992). The picture superiority effect in categorization: Visual or semantic? Journal of Experimental Psychology: Learning, Memory, \& Cognition, 18, 1019-1028.

KROLL, J. F. (1990). Recognizing words and pictures in sentence contexts: A test of lexical modularity. Journal of Experimental Psychology: Learning, Memory, \& Cognition, 16, 747-759.

Kroll, J. F., \& PotTer, M. C. (1984). Recognizing words, pictures and concepts: A comparison of lexical, object and reality decisions. Journal of Verbal Learning \& Verbal Behavior, 23, 39-66.

Levelt, W. J. M., Schriefers, H., Vorberg, D., Meyer, A. S., PechMANN, T., \& HavinGA, J. (1991). The time course of lexical access in speech production: A study of picture naming. Psychological Review, 98, 122-142.

LLOYD-JONES, T. J. (1992). Category differences in object processing. Unpublished doctoral dissertation, University of London.

Lloyd-Jones, T. J., \& HumphreYs, G. W. (1996). Categorizing pears and naming chairs: Category differences in object processing as a function of task and priming. Manuscript submitted for publication.

LofTus, G. R., \& MASSON, M. E. (1994). Using confidence intervals in within-subject designs. Psychonomic Bulletin \& Review, 1, 476-490.

LUPKER, S. J. (1985). Relatedness effects in word and picture naming: Parallels, differences, and structural implications. In A. W. Ellis (Ed.), Progress in the psychology of language (Vol. 1, pp. 109-142). Hillsdale, NJ: Erlbaum.

LUPKER, S. J. (1988). Picture naming: An investigation of the nature of categorical priming. Journal of Experimental Psychology: Learning, Memory, \& Cognition, 14, 444-455.

Monsell, S. (1985). Repetition and the lexicon. In A. W. Ellis (Ed.), Progress in the psychology of language (Vol. 2, pp. 147-195). Hillsdale, NJ: Erlbaum.

OLDFIELD, R. C., \& WINGFIELD, A. (1965). Response latencies in naming objects. Quarterly Journal of Experimental Psychology, 27 273-281

Price, C. J., \& Humphreys, G. W. (1989). The effects of surface detail on object categorization and naming. Quarterly Journal of Experimental Psychology, 41A, 797-828.

RidDoch, M. J., \& Humphreys, G. W. (1987a). Picture naming. In G. W. Humphreys \& M. J. Riddoch (Eds.), Visual object processing: A cognitive neuropsychological approach (pp. 107-143). Hove: Erlbaum.

RidDOCH, M. J., \& HumPHREYs, G. W. (1987b). Visual object processing in optic aphasia: A case of semantic access agnosia. Cognitive Neuropsychology, 4, 131-185.

Rosch, E. (1975). Cognitive representations of semantic categories. Journal of Experimental Psychology: General, 104, 192-233.

SACChetT, C., \& Humphreys, G. W. (1992). Calling a squirrel a squirrel but a canoe a wigwam: A category-specific deficit for artefactual objects and body parts. Cognitive Neuropsychology, 9, 73-96.

SARTORI, G., \& JOB, R. (1988). The oyster with four legs: A neuropsychological study of the interaction of visual and semantic information. Cognitive Neuropsychology, 5, 105-132.

SARTORI, G., JOB, R., \& COlTHEART, M. (1993). The neuropsychology of visual semantics. In D. E. Meyer \& S. Kornblum (Eds.), Attention and performance XIV. Cambridge, MA: MIT Press.

SChacter, D. L., CoOper, L. A., \& Delaney, S. M. (1990a). Implicit memory for visual objects and the structural description system. Bulletin of the Psychonomic Society, 28, 367-372.

Schacter, D. L., CoOPer, L. A., \& Delaney, S. M. (1990b). Implicit memory for unfamiliar objects depends on access to structural descriptions. Journal of Experimental Psychology; General, 119, 5-24.

Schacter, D. L., Cooper, L. A., Delaney, S. M., Peterson, M. A., \&
THARaN, M. (1991). Implicit memory for possible and impossible objects: Constraints on the construction of structural descriptions. Journal of Experimental Psychology; Learning, Memory, \& Cognition, 17, 3-19.

SChaEFFER, B., \& Wallace, R. (1969). Semantic similarity and the comparison of word meanings. Journal of Experimental Psychology, 82, 343-346.

Seymour, P. H. K. (1979). Human visual cognition. London: Collier MacMillan.

Sheridan, J., \& Humphreys, G. W. (1993). A verbal-semantic category-specific recognition impairment. Cognitive Neuropsychology, 10, 143-184.

SHOBEN, E. J. (1976). The verification of semantic relations in a samedifferent paradigm: An asymmetry in semantic memory. Journal of Verbal Learning \& Verbal Behavior, 15, 365-379.

Silveri, M. C., \& GAINOTTI, G. (1988). Interaction between vision and language in a category-specific semantic impairment. Cognitive Neuropsychology, 5, 677-709.

SNODGRass, J. G. (1984). Concepts and their surface representations. Journal of Verbal Learning \& Verbal Behavior, 23, 3-22.

SNODGRASS, J. G., \& VANDERWART, M. (1980). Standardized set of 260 pictures: Norms of name agreement, usage agreement, familiarity, and visual complexity. Journal of Experimental Psychology: Human Learning \& Memory, 6, 174-215.

STERNBERG, S. (1969). The discovery of processing stages: Extensions of Donders' method. Acta Psychologica, 30, 276-315.

Stewart, F., Parkin, A. J., \& Hunkin, N. M. (1992). Naming impairments following recovery from herpes simplex encephalitis: Category-specific? Quarterly Journal of Experimental Psychology, 44, 261-284.

VitKovitch, M., Humphreys, G. W., \& Lloyd-Jones, T. J. (1993). On naming a giraffe a zebra: Picture naming errors across different $o b-$ ject categories. Journal of Experimental Psychology: Learning, Memory, \& Cognition, 19, 243-259.

WARREN, C. E. J., \& MORTON, J. (1982). The effects of priming on picture naming. British Journal of Psychology, 73, 117-130.

WARRINGTON, E. K., \& MCCARTHY, R. (1983). Category specific access dysphasia. Brain, 106, 859-878.

WARRINGTON, E. K., \& MCCARTHY, R. (1987). Categories of knowledge: Further fractionation and an attempted integration. Brain, $110,1273-1296$

Warrington, E. K., \& Shallice, T. (1984). Category specific semantic impairments. Brain, 107, 829-853.

WHEELDON, L. R., \& MONSELL, S. (1992). The locus of repetition priming of spoken word production. Quarterly Journal of Experimental Psychology, 44, 723-761.

\section{NOTES}

1. Latencies $\pm 2 S D$ s from each subject's mean in each condition were counted as errors in the analyses of the experiment, and following this, items for which accuracy was $<62.5 \%$ were dropped from the analyses (this criterion meant that there were at least $10 \mathrm{RT}$ gathered for each cell in the subject and item analyses). Furthermore, each analysis was carried out twice, once dropping items with fewer than 10 RTs, and once using the RTs left after counting those RTs less than or greater than $2 S D$ s as errors, no matter how few RTs were left for each item. The outcome of both sets of analyses was the same in all cases, since these procedures affected only a small percentage of total items.

2. We also repeated the ANCOVA including name agreement as a covariate. The results of the analysis were unaffected.

3 . Fillers were not used to equate intertask lag. This would have increased the duration of the experiment, making fatigue effects probable. In addition, although unlikely, fillers may have altered the nature of the tasks. For example, increasing the number of object trials for the naming prime task group relative to the object decision prime task group would have meant that many categories were activated for naming relative to only four for object decision. This may have resulted in greater semantic or associative priming (within the prime task or on 
subsequent naming), or, for example, in greater task difficulty or alertness for naming.

4. Multiple regressions were carried out on baseline RTs for each condition. For naming, both log name frequency and familiarity were significant predictors for both conditions: (1) for the naming-naming condition, $R^{2}=37.9 \%, \log$ name frequency regression coefficient $=$ $-2.0( \pm 0.9), t$ ratio $=-2.1, p<.05$; familiarity regression coefficient $=-136.2( \pm 25.0), t$ ratio $=-5.4, p<.0001 ;(2)$ for the object decision-naming condition, $R^{2}=26.6 \%$, log name frequency regression coefficient $=-2.9( \pm 1.3), t$ ratio $=-2.4, p<.05$; familiarity regression coefficient $=-124.0( \pm 34.1), t$ ratio $=-3.6, p<.0005$. In contrast, for object decision, neither independent variable was a significant predictor for either condition: (1) for the naming-object decision condition, $R^{2}=5 \%, \log$ name frequency regression coefficient $=-0.4( \pm 0.4), t$ ratio $=-1.1, p=$ n.s.; familiarity regression coefficient $=-12.3( \pm 10.4), t$ ratio $=-1.1, p=$ n.s. (2) for the object decision-object decision condition, $R^{2}=2.4 \%$, log name frequency regression coefficient $=-0.3( \pm 0.3), t$ ratio $=-1.0, p=$ n.s.; familiarity regression coefficient $=-3.8( \pm 7.6), t$ ratio $=-0.5$, $p=\mathrm{n} . \mathrm{s}$.

5. Note that matching the stimuli in this way has the disadvantage that the number of categories cannot be easily equated.

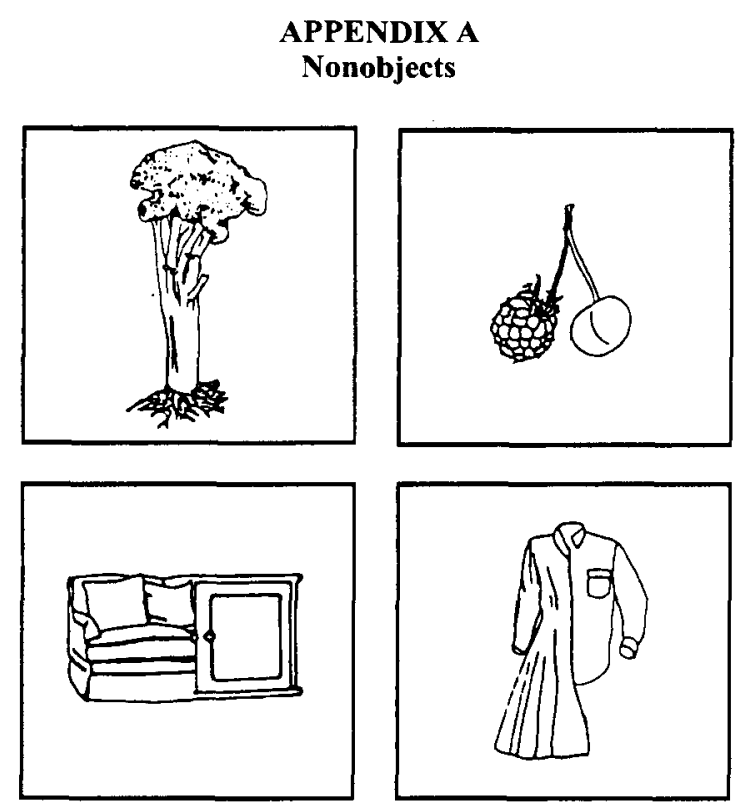

\section{APPENDIX B \\ List of Items Used in Experiment 1}

Clothing: shirt, sock, coat, jacket, tights, watch, earring, hat, jumper, trousers, bra, dress, shoes, belt, vest, scarf, tie, glove.

Furniture: dresser, mirror, ironing board, hoover [vacuum cleaner], chair, stool, lamp, bed, vase, telephone, television, sofa, shelves, clock, cupboard, rug, table, desk.

Fruit: pear, prune, avocado, pineapple, pomegranate, melon, olive, cherry, date, fig, banana, strawberry, coconut, lemon, apple, raspberry, grapefruit, grapes.

Vegetables: sweet corn, potato, asparagus, carrot, leek, lettuce, onion, bean, turnip, radish, watercress, artichoke, garlic, aubergine [eggplant], mushroom, courgette [zucchini], rice, pepper.

\section{APPENDIX C \\ Name Frequency, Prototypicality, and Familiarity: Analyses of Covariance}

It is possible that the category differences that we have observed were inflated by other factors affecting picture recognition and naming, most notably: name frequency, prototypicality, and familiarity. To assess performance with these factors taken into account, an ANCOVA was carried out with these variables as covariates. Frequency values for the names of each picture were obtained from Francis and Kucera's (1982) frequency analysis of English usage. ' Prototypicality ratings were obtained from Rosch's (1975) norms, and familiarity ratings were collected from 10 independent subjects, who received instructions similar to those used by Snodgrass and Vanderwart (1980). We also obtained ratings from 10 subjects as to the item complexity (on a scale of $1-5$ ); however, since there was little difference between structurally similar and structurally dissimilar categories on these scores, and since the difference was in different directions for Experiment 1 and Experiment 2 (where there were additional items), we did not include complexity as a covariate (structurally similar Experiment $1=$ 3.39 , structurally dissimilar Experiment $1=2.92$, structurally similar Experiment $2=2.88$, structurally dissimilar Experiment $2=3.01$ ). Table $\mathrm{C} 1$ gives the mean ratings on these measures for each category. ${ }^{2}$ For familiarity, name frequency, and complexity, the higher the number, the more familiar, frequent, and complex. For prototypicality, the higher the number, the less prototypical. Three stimuli (courgette [zucchini], hoover [vacuum cleaner], and ironing board) were dropped from the analysis of covariance, since there were no prototypicality ratings for these items.

\section{Experiment 1: Analysis of Covariance}

There was a main effect of category $\left[F_{2}(1,64)=29.93\right.$, $\left.M S_{\mathrm{e}}=16,395, p<.0001\right]$, a main effect of task $\left[F_{2}(1,64)=\right.$ $\left.25.75, M S_{\mathrm{e}}=13,406, p<.0001\right]$, and a category $\times$ task interaction $\left[F_{2}(1,64)=13.08, M S_{\mathrm{e}}=13,406, p<.001\right]$. There was a significant task $\times$ task order interaction $\left[F_{2}(1,64)=4.46\right.$, $p<.05]$. No other main effects or interactions were significant [the three way interaction was not significant $F_{2}(3,62)=$ $1.15]$. For the covariates, only familiarity approached significance $\left[F_{2}(1,64)=3.23, M S_{\mathrm{e}}=16,395, p=.077\right]$. For both prototypicality and name frequency, $F_{2}<1.0$.

The category $\times$ task interaction was further analyzed using planned comparisons on the adjusted cell means (the least squares means), with the appropriate adjusted mean square error term. For both naming and object decision, responses were significantly slower to structurally similar items than to structurally dissimilar items (both $p s<.01$ ). However, the category difference was greater for naming. The least squares means are given in Table 1.

Thus, when the effect of the covariates is partialled out, the strong relationship between category and task remains.

\section{Experiment 2: Analysis of Covariance}

The same measures from the same sources as in Experiment 1 were used. Five items were dropped from the analysis, since no prototypicality ratings were available (courgette [zucchini], hoover [vacuum cleaner], ironing board, toaster, and glasses)

For the RPE analysis, there was a main effect of category $\left[F_{2}(1,86)=8.75, M S_{\mathrm{e}}=21,191, p<.005\right]$, and a category $\times$ target task interaction $\left[F_{2}(1,86)=6.90, M S_{\mathrm{e}}=15,440, p<\right.$ 
Table C1

Mean Familiarity, Prototypicality Ratings, Name Frequencies, and Complexity Ratings for Each Category, With Standard Deviations (SDs)

\begin{tabular}{|c|c|c|c|c|c|c|c|c|}
\hline \multirow[b]{2}{*}{ Category } & \multicolumn{2}{|c|}{ Familiarity } & \multicolumn{2}{|c|}{ Prototypicality } & \multicolumn{2}{|c|}{$\begin{array}{c}\text { Name } \\
\text { Frequency }\end{array}$} & \multicolumn{2}{|c|}{ Complexity } \\
\hline & $M$ & $\overline{S D}$ & $M$ & $S D$ & $M$ & $S D$ & $M$ & $S D$ \\
\hline thrally diccimil & 4.10 & 0. & 3.46 & 1.82 & 25.20 & 31.51 & 3.01 & 0.8 \\
\hline Structurally similar & 3.13 & 0.90 & 2.51 & 1.32 & 4.32 & 6.6 & 2.88 & 1. \\
\hline
\end{tabular}

.05]. No other main effects or interactions were significant (including the three-way interaction, $F_{2}<1$ ). None of the covariates were significant. Planned comparisons on adjusted cell means using the appropriate adjusted mean square error term revealed that for naming, there was greater priming for structurally similar than for structurally dissimilar items ( $p<$ .01 ); for object decision there were no significant differences.

For the baseline analysis, there was a main effect of category $\left[F_{2}(1,86)=63.84, M S_{\mathrm{e}}=31,487, p<.0001\right]$. Further there was a main effect of target task $\left[F_{2}(1,86)=36.05\right.$, $\left.M S_{\mathrm{e}}=22,103, p<.0001\right]$, and a category $\times$ target task interaction $\left[F_{2}(1,86)=47.91, M S_{\mathrm{e}}=22,103, p<.0001\right]$. None of the covariates was significant [ for familiarity, $F_{2}(1,86)=2.11$ ]; for prototypicality, $F_{2}<1$; and for name frequency, $F_{2}(1,86)=$ 2.30]. Planned comparisons on adjusted cell means using the appropriate adjusted mean square error term revealed that for both naming and object decision, responses were slower to structurally similar than to structurally dissimilar items $(p<.01)$. Nevertheless, differences were much greater for naming than for object decision (338-msec vs. 54-msec differences for naming and object decision, respectively).

As with Experiment 1, the strong relationship between task and category remained when the effects of the covariates had been controlled.

\section{NOTES}

1. In fact two ANCOVAs were carried out, each using different measures of name frequency. The first used the value relating to the singular or mass noun only. The second used the stem frequency count, which refers to words having the same stem and/or meaning and belonging to the same major word class, differing only in inflection and/or spelling. Because the results obtained were identical, only the second analysis is reported for this and subsequent experiments. A further point to note is that $\log$ name frequency was used rather than untransformed name frequency values (see Oldfield \& Wingfield, 1965). This was the case for all reported experiments.

2 . The means are derived from the full set of items used in Experiments 1 and 2, minus five items for which there were no prototypicality ratings (courgette, hoover, ironing board, toaster, and glasses). Therefore these means are from Experiment 2 item sets, which include an additional 19 items to those used in Experiment 1.

\section{APPENDIX D}

\section{Additional Items Used in Experiment 2}

Clothing: waistcoat, ring, skirt, blouse, glasses, handbag. Furniture: fridge, piano, stereo, toaster, cooker, ashtray. Fruit: gooseberry, orange, peach, plum, apricot, pumpkin. Vegetables: celery, parsley, cucumber, radish, sprout, marrow.

\section{APPENDIX E}

\section{Experiment 2: Primed RT Analyses}

In order to examine whether the equivalent priming effects on naming, from both naming and object decision as prime tasks, were due to the fact that performance was at ceiling (i.e., there was no more room for within-task improvement), an analysis of primed (target task) scores was carried out.

There was a main effect of target task $\left[F_{1}(1,60)=136.89\right.$, $M S_{\mathrm{e}}=16,311, p<.0001 ; F_{2}(1,94)=428.30, M S_{\mathrm{e}}=13,922$, $p<.0001]$. Further, there was a main effect of category $\left[F_{1}(1,60)=204.84, M S_{\mathrm{e}}=5,071, p<.0001 ; F_{2}(1,94)=\right.$ $\left.127.22, M S_{\mathrm{e}}=20,403, p<.0001\right]$, and a target task $\times$ category interaction $\left[F_{1}(1,60)=133.16, M S_{\mathrm{e}}=5,071, p<.0001\right.$; $\left.F_{2}(1,94)=113.69, M S_{\mathrm{e}}=13,992, p<.0001\right]$. By items only, there was also a prime task $\times$ target task interaction $\left[F_{1}(1,60)=\right.$ $\left.1.01, F_{2}(1,94)=5.12, M S_{\mathrm{e}}=7,261, p<.05\right]$. No other main effects or interactions were significant, including the threeway interaction $\left[F_{1}(1,60)=1.97 ; F_{2}(1,94)=2.07\right]$.

For both naming and object decision, planned comparisons showed that responses were slower to structurally similar items than to structurally dissimilar items $(p s<.01)$. However, the difference was much greater for naming ( $325 \mathrm{msec}$ for naming vs. $34 \mathrm{msec}$ for object decision).

Planned comparisons of the prime task $\times$ target task interaction (by items) showed that naming as the target task was slower than object decision, though this difference was larger for the group that had object decision as the prime task $(p \mathrm{~s}<$ .01 ; the means were as follows: object decision prime-object decision target, $628 \mathrm{msec}$; object decision prime-naming target, $897 \mathrm{msec}$; naming prime-object decision target, $652 \mathrm{msec}$; naming prime-naming target, $882 \mathrm{msec}$ ).

One reason why priming effects on naming might have been equivalent for naming and object decision as prime tasks is that RTs in the naming task could not improve further. Were that the case, there would be no room for further benefits in the naming condition relative to when subjects made object decisions to primes. However, as is clear from these analyses, differences are still apparent in the RTs to primed targets: RTs remained slower to structurally similar items than to structurally dissimilar items. Task-specific priming (from naming as the prime task onto naming as the target task) could have emerged with structurally similar items, but none was evident.

\section{APPENDIX F \\ Replicating the Naming Then Naming Condition of Experiment 2 With More Categories of Item}

Seventy-two items were selected from Snodgrass and Vanderwart (1980). Structurally similar items had an average contour overlap rating of $16.7(S D=4.73)$; structurally dissimilar items, an average contour overlap rating of $12.6(S D=4.75)$. The items were as follows:

Structurally similar (SS): Bear, bee, beetle, camel, carrot, cat, celery, chicken, corn, cow, deer, dog, elephant, fly, fox, giraffe, gorilla, horse, kangaroo, lettuce, lion, mouse, mushroom, onion, orange, owl, pear, pepper, potato, rabbit, rhino, sheep, spider, squirrel, tiger, zebra.

Structurally dissimilar (SD): Airplane, ashtray, axe, bed. blouse, bowl, broom, button, chisel, clock, cup, doorknob, 
drum, helicopter, kettle, kite, lips, lock, nail, necklace, nut, pencil, pipe, pliers, refrigerator, ring, ruler, saltshaker, scissors, screw, shoe, stool, stove, television, toaster, vase.

The familiarity ratings were as follows: $\mathrm{SS}=2.70(\mathrm{SD}=$ $0.78), \mathrm{SD}=3.64(S D=0.77)$. The complexity ratings were $\mathrm{SS}=3.59(S D=0.75), \mathrm{SD}=2.58(S D=0.59)$. Francis and Kucera's (1982) name frequency ratings were $S S=16.83$ $(S D=24), S D=17.52(S D=24.98)$. Humphreys et al.'s (1988) prototypicality ratings were $S S=2.47(S D=0.92)$, $\mathrm{SD}=3.61(S D=1.45)$.

The same method, design, and procedure were used as in Experiment 2, with 10 subjects who had not seen the pictures before and had not participated in any of the previous experiments. Following data collation, five items were dropped, since 6 or more subjects made errors to those items: tiger, bee, blouse, saltshaker, and chisel.

A repeated measures ANOVA was carried out with category (SS vs. SD) and priming (unprimed vs. primed) as factors. There was a main effect of category, with longer RTs to SS items $\left[F_{1}(1,9)=32.02, M S_{\mathrm{e}}=27,090, p<.0003 ; F_{2}(1,65)=\right.$ $\left.11.19, M S_{\mathrm{e}}=38,613, p<.005\right]$, and a main effect of priming, with longer RTs to unprimed items $\left[F_{1}(1,9)=31.02, M S_{\mathrm{e}}=\right.$ $\left.9,141, p<.0003 ; F_{2}(1,65)=4.46, M S_{\mathrm{e}}=21,222, p<.0001\right]$. There was also a category $\times$ priming interaction $\left[F_{1}(1,9)=\right.$ $13.61, M S_{\mathrm{e}}=936, p<.01 ; F_{2}(1,65)=4.46, M S_{\mathrm{e}}=21,222$, $p<.05]$. Planned comparisons showed a difference between unprimed and primed scores for both SS and SD $(p \mathrm{~s}<.01 ; \mathrm{SS}$ unprimed $=1,008 \mathrm{msec}$, SS primed $=804 \mathrm{msec}$, SD unprimed $=872 \mathrm{msec}$, SD primed $=739 \mathrm{msec}$ ). However, the difference between unprimed and primed was greater for SS items (204 vs. $132 \mathrm{msec}$ ).

There were no main effects or interactions for the error analyses $(\mathrm{SS}$ unprimed $=0.7, \mathrm{SS}$ primed $=0.6, \mathrm{SD}$ unprimed $=$ $0.6, \mathrm{SD}$ primed $=0.35$ )

A multiple regression analysis was carried out on the unprimed baseline scores with contour overlap, familiarity, complexity, name frequency, and prototypicality as regressors. The multiple regression was significant $\left[R^{2}=23 \%, F(5,61)=\right.$ $\left.3.62, M S_{\mathrm{e}}=48,238, p<.01\right]$, but the only significant regressor was contour overlap: contour overlap regression coefficient $=13.12, t$ ratio $=2.22( \pm 5.89), p<.05$; familiarity regression coefficient $=-39.97, t$ ratio $=-.77( \pm 35.03), p=$ n.s.; complexity regression coefficient $=8.46, t$ ratio $=1.56$ $( \pm 5.41), p=$ n.s.; name frequency regression coefficient $=$ $-.93, t$ ratio $=-.77( \pm 1.2), p=$ n.s.; prototypicality regression coefficient $=-8.82, t$ ratio $=-.40( \pm 21.89), p=$ n.s.

(Manuscript received April 12, 1995; revision accepted for publication November 5, 1995.) 